\title{
Integration of Genome-Wide Computation DRE Search, AhR ChIP-chip and Gene Expression Analyses of TCDD-Elicited Responses in the Mouse Liver
}

\author{
Edward Dere', Raymond Lo², Trine Celius², Jason Matthews ${ }^{2}$ and Timothy R Zacharewski ${ }^{13^{*}}$
}

\begin{abstract}
Background: The aryl hydrocarbon receptor (AhR) is a ligand-activated transcription factor (TF) that mediates responses to 2,3,7,8-tetrachlorodibenzo-p-dioxin (TCDD). Integration of TCDD-induced genome-wide AhR enrichment, differential gene expression and computational dioxin response element (DRE) analyses further elucidate the hepatic AhR regulatory network.

Results: Global ChIP-chip and gene expression analyses were performed on hepatic tissue from immature ovariectomized mice orally gavaged with $30 \mu \mathrm{g} / \mathrm{kg}$ TCDD. ChIP-chip analysis identified 14,446 and 974 AhR enriched regions (1\% false discovery rate) at 2 and $24 \mathrm{hrs}$, respectively. Enrichment density was greatest in the proximal promoter, and more specifically, within $\pm 1.5 \mathrm{~kb}$ of a transcriptional start site (TSS). AhR enrichment also occurred distal to a TSS (e.g. intergenic DNA and 3' UTR), extending the potential gene expression regulatory roles of the AhR. Although TF binding site analyses identified over-represented DRE sequences within enriched regions, approximately 50\% of all AhR enriched regions lacked a DRE core (5'-GCGTG-3'). Microarray analysis identified 1,896 number of TCDD-responsive genes (|fold change| $\geq 1.5, \mathrm{P} 1(\mathrm{t})>0.999)$. Integrating this gene expression data with our ChIP-chip and DRE analyses only identified 625 differentially expressed genes that involved an AhR interaction at a DRE. Functional annotation analysis of differentially regulated genes associated with AhR enrichment identified overrepresented processes related to fatty acid and lipid metabolism and transport, and xenobiotic metabolism, which are consistent with TCDD-elicited steatosis in the mouse liver.

Conclusions: Details of the AhR regulatory network have been expanded to include AhR-DNA interactions within intragenic and intergenic genomic regions. Moreover, the AhR can interact with DNA independent of a DRE core suggesting there are alternative mechanisms of AhR-mediated gene regulation.
\end{abstract}

\section{Background}

The aryl hydrocarbon receptor (AhR) is a ligand activated transcription factor (TF) belonging to the basic-helixloop-helix-PAS (bHLH-PAS) family of proteins that serve as environmental sensors [1]. 2,3,7,8-Tetrachlorodibenzo$p$-dioxin (TCDD) is the prototypical AhR ligand, a ubiquitous environmental contaminant that elicits diverse species-specific effects, including tumor promotion, teratogenesis, hepatotoxicity, modulation of endocrine

\footnotetext{
* Correspondence: tzachare@msu.edu

'Department of Biochemistry \& Molecular Biology, Michigan State University, East Lansing, Ml, 48824, USA

Full list of author information is available at the end of the article
}

systems, immunotoxicity and enzyme induction $[2,3]$. These effects result from alterations in gene expression mediated by the AhR [4]. Several studies have demonstrated the requirement for the AhR in mediating TCDD-elicited responses. For example, mice carrying low-affinity AhR alleles are less susceptible to the effects elicited by TCDD [5]. Additionally, AhR-null mice fail to induce responses typically observed following treatment with TCDD and related compounds [6].

TCDD binding to the cytosolic AhR results in a conformational change and translocation to the nucleus. The activated AhR complex heterodimerizes with the aryl hydrocarbon nuclear translocator (ARNT), another

\section{Biomed Central}


bHLH-PAS family member, and binds dioxin response elements (DREs) containing the substitution intolerant 5'-GCGTG-3' core sequence to regulate changes in gene expression [4,7]. Computational searches for all DRE cores in the human, mouse and rat genome identified the highest density of DREs proximal to a transcriptional start site (TSS) [8]. However, a significant number of DRE cores and putative functional DREs have been identified in distal regions within non-coding intergenic segments of the genome. It has been proposed that enrichments for other TFs on outlying regions may be functionally relevant through tertiary looping of genomic DNA and/or via protein tethering mechanisms [9].

The role of specific transcriptional regulators has been studied on a gene-by-gene basis, primarily focusing on regions proximal to the TSS. However, the coupling of chromatin immunoprecipitation with either genomic tiling microarrays (ChIP-chip) or next-generation sequencing (ChIP-seq) has facilitated genome-wide analysis of protein-DNA interactions for a variety of receptors [10-16], TFs [17-20] and components of the basal transcriptional machinery $[10,21,22]$. Genome-wide location analyses further suggest that TF binding at cis-regulatory enhancers in intergenic DNA regions of the genome may also have functional significance $[10,17,23,24]$.

Several studies have investigated AhR-mediated gene expression responses using various technologies [25-30]. Although AhR-DNA interactions have primarily focused on the regulation of CYP1A1 [4,31], recent global ChIP studies have extended our knowledge of AhR-DNA interactions by examining promoter region binding profiles using in vitro and in vivo models [32-35] (Lo et al., in submission). Our study provides a comprehensive analysis by examining TCDD-induced AhR binding across the entire mouse genome. In addition, we examined AhR binding within chromosomes, intragenic and intergenic DNA regions, and in specific genic regions (i.e., $10 \mathrm{~kb}$ upstream of a TSS, 5' and 3' untranslated regions [UTRs], coding sequence [CDS]). Global AhR enrichment data are also integrated with computational DRE core analysis [8], and complementary whole-genome gene expression profiling to provide a more comprehensive evaluation of the hepatic AhR regulatory network elicited by TCDD.

\section{Results \\ Identification and Characterization of TCDD-Elicited AhR Enrichment}

In order to identify regions of AhR enrichment induced by TCDD across the genome, ChIP-chip assays were performed using hepatic tissue from immature ovariectomized mice orally gavaged with $30 \mu \mathrm{g} / \mathrm{kg}$ TCDD for 2 and $24 \mathrm{hrs}$. CisGenome [36] analysis identified 22,502 and 12,677 enriched regions at 2 and 24 hrs, respectively. Applying a conservative FDR of 0.01 resulted in 14,446 and 974 significant AhR enriched regions at 2 and $24 \mathrm{hrs,}$ respectively (Additional Files 1 and 2 provides a complete list of enriched regions). Ligand activation of the AhR in vivo triggers its own rapid degradation and causing a significant reduction of AhR levels [37,38]. This is reflected in the significantly lower number of TCDDinduced AhR enriched regions at $24 \mathrm{hrs}$ as compared to 2 hrs. The distribution, location and enrichment values for each tiled probes across the Cyp1a1 gene (represented by RefSeq sequences NM_009992 and NM_001136059) are summarized in Figure 1. MA value plots visualize the profile of the enriched region and $\log _{2}$ fold-enrichment values for each probe are also illustrated (Figure 1). Note that the probes are unevenly tiled throughout the genome, resulting in gaps in genome coverage that may coincide with DRE core locations that may affect AhR enriched region identification. For example, two enriched regions were associated with Cyp1a1 (Figure 1, red bars). However, the MA plots for 2 and 24 hrs suggest that there is only one large region of enrichment divided into two as a result of the uneven tiling. Consequently, uneven tiling and the lack of tiling in regions that contain DREs may affect the estimated number of AhR enriched regions.

Genomic regions with significant AhR enrichment were mapped to intragenic ( $10 \mathrm{~kb}$ upstream of a TSS plus the transcribed gene of mature RefSeq sequences) and noncoding intergenic regions (Table 1; Additional File 3). Most regions were enriched 5.7-fold with values ranging from 1.7- to 111.4-fold (Figures 2A-B). Enriched regions varied in width from 108 to 6,990 bp (Figure 2C) with $90.5 \%$ spanning $\leq 1,500 \mathrm{bp}$. There was no correlation between fold enrichment and region width (data not shown). Of the 974 significantly enriched regions at $24 \mathrm{~h} 899$ of them overlapped with a $2 \mathrm{hr}$ enriched region (Figure 2D), consistent with reports of constant shuttling of the AhR between the nucleus and cytoplasm [39], and AhR promoter occupancy of targeted genes in untreated cells [34]. Relaxing the FDR to 0.05 increased the overlap to 906, while reducing the number of $24 \mathrm{hr}$ specific enriched regions to 68 . Comparable overlaps were identified in promoter-specific ChIP-chip studies of TCDD-induced AhR enrichment at 2 and 24 hrs in the livers of intact C57BL/6 mice, which identified 1,397 number of genes with 403 overlap (Lo et al., in submission). Further analysis of the 899 enriched regions found that the fold enrichment values from both time points were positively correlated (Pearson correlation coefficient $=0.4853$, two-tailed p-value $<0.0001$; Figure 2E). Although only $40 \%$ of the mouse genome consists of intragenic DNA, $71.8 \%$ and $64.7 \%$ of all sites with significant AhR enrichment at 2 hrs and 24 hrs, respectively, were within this region. The density of AhR enrichment (per million base pairs [Mbp]) was calculated across the entire genome in order to consider the cumulative 


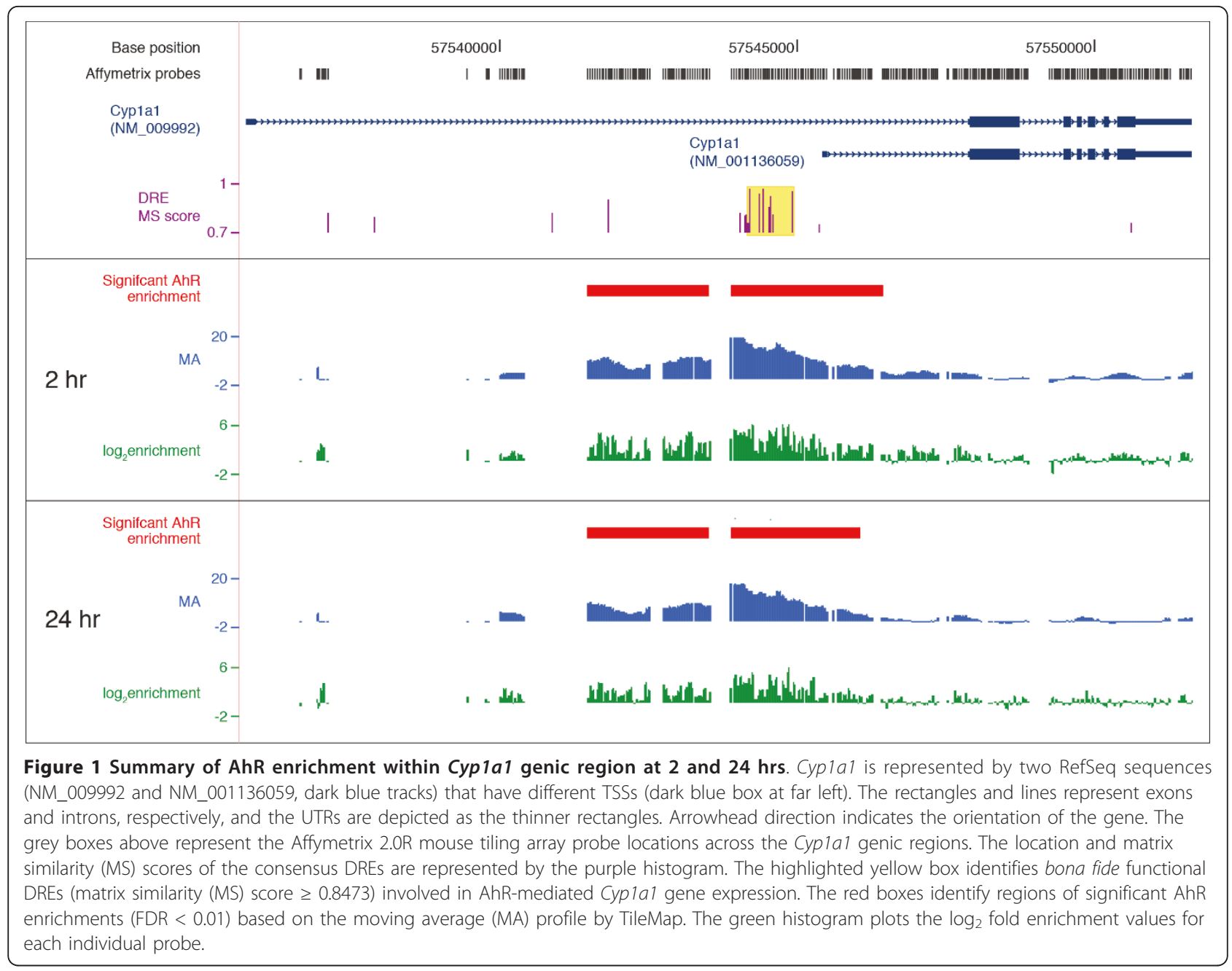

intergenic and intragenic DNA region lengths (Table 1). Genome and chromosomal analyses (Additional Files 4 and 5) revealed increased enrichment within intragenic regions compared to non-coding intergenic regions further illustrating a bias for gene encoding regions. However, these values may be inflated due to incomplete probe coverage in the intergenic regions and sequence gaps in the genome. Specific analysis of the 10 kb upstream, 5' and 3' UTRs and CDS regions revealed the highest density of AhR enrichment was proximal to the TSS (Table 1 and Additional Files 4 and 5). AhR enrichment density was greatest within $\pm 1.5 \mathrm{~kb}$ at 2 and 24 hrs (Figures $3 \mathrm{~A}-\mathrm{B}$ ), coinciding with proximal promoter DRE core densities [8] and RNA polymerase II binding at the TSSs [10]. Interestingly, there is a notable cleft in AhR enrichment 200 bp directly upstream and downstream of the TSSs, possibly to accommodate general transcription machinery. Both global and

Table 1 Distribution and density analysis of TCDD-induced AhR enriched regions ${ }^{\mathrm{a}}$ in the mouse genome

\begin{tabular}{|c|c|c|c|c|c|c|c|c|}
\hline & & \multirow[b]{2}{*}{ Genome } & \multirow[b]{2}{*}{ Intergenic DNA ${ }^{\mathrm{b}}$} & \multirow[b]{2}{*}{ Intragenic DNA ${ }^{b}$} & \multicolumn{4}{|c|}{ Genic Regionc } \\
\hline & & & & & $10 \mathrm{~kb}$ upstream & 5' UTR & CDS & 3' UTR \\
\hline \multirow[t]{2}{*}{$2 \mathrm{hr}$} & AhR enrichment & 14,446 & 4,163 & 10,283 & 4,601 & 2,569 & 7,499 & 225 \\
\hline & Enrichment density $^{d}$ & 5.44 & 2.62 & 9.64 & 18.65 & 17.29 & 7.21 & 7.29 \\
\hline \multirow[t]{2}{*}{$24 \mathrm{hr}$} & AhR enrichment & 974 & 344 & 630 & 306 & 132 & 507 & 9 \\
\hline & Enrichment density ${ }^{d}$ & 0.37 & 0.22 & 0.59 & 1.24 & 0.89 & 0.49 & 0.29 \\
\hline
\end{tabular}

${ }^{a}$ AhR enriched regions with a FDR $<0.01$

${ }^{\mathrm{b}}$ intergenic, intragenic and gene regions are defined as previously described in Additional File 1

c regions are defined using the genomic locations in the refGene database from the UCSC Genome Browser

${ }^{d}$ density calculated per million base pairs 


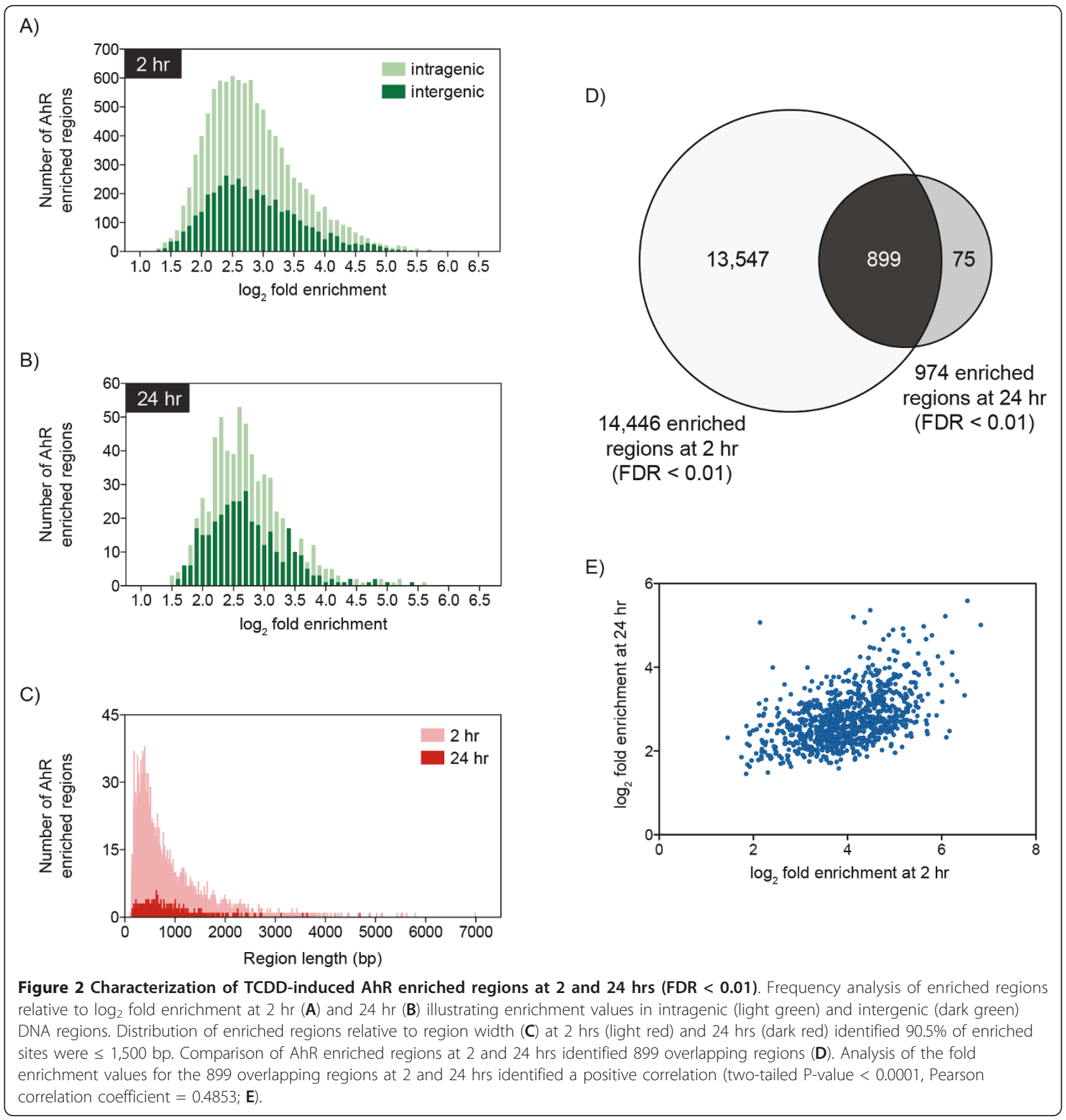

proximal promoter density analyses illustrate TCDDinduced $A h R$ enrichments are more prominent in regions directly associated with a gene. Nevertheless, there are a significant number of distally located enrichment sites that may also be functionally relevant.

\section{Confirmation of AhR ChIP-chip Enrichment Analysis}

Selected regions of AhR enrichment identified by ChIPchip analysis at $2 \mathrm{hrs}$ were confirmed by ChIP-PCR (Figure 4). Three representative ChIP-chip enrichments from each genomic region (intergenic, $10 \mathrm{~kb}$ upstream of a TSS, 5' UTR, CDS and 3' UTR) were selected to validate AhR enrichments with and without a DRE core at different positions relative to the TSS. ChIP-PCR and ChIP-chip analysis of DRE containing regions exhibited similar levels of $A h R$ enrichment relative to $\operatorname{IgG}_{\mathrm{TCDD}}$ controls and were significantly greater than vehicle controls relative to $\operatorname{IgG}_{\text {vehicle. }}$ AhR enriched regions without the DRE core were also verified, further demonstrating that the AhR can interact with DNA independent of a 


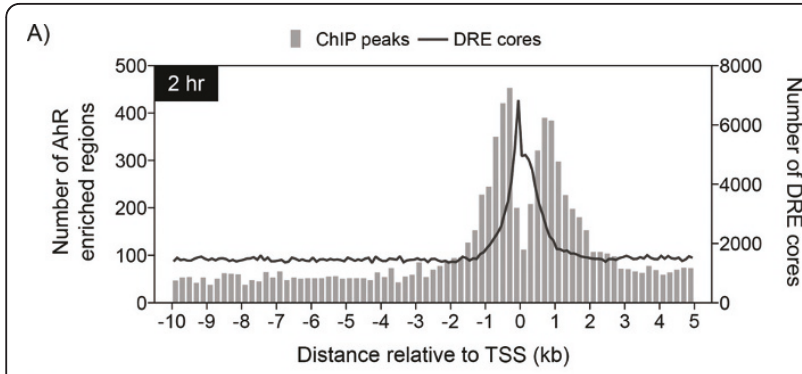

B)

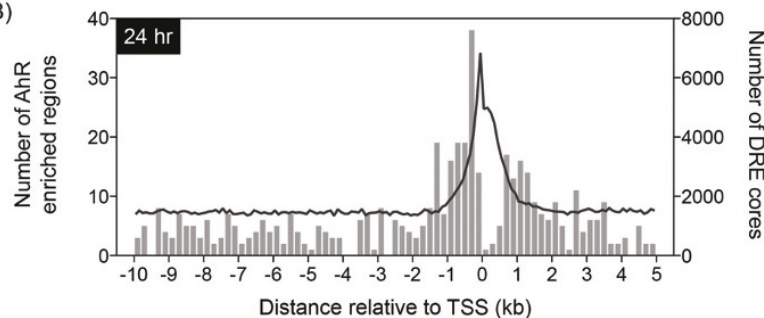

Figure 3 TCDD-induced AhR enrichment (FDR $<0.01$ ) densities in the proximal promoter (10 kb upstream and $5 \mathrm{~kb}$ downstream of a TSS) at 2 hrs (A) and 24 hrs (B). The bars represent the number of enriched regions in each $200 \mathrm{bp}$ window. The number of DRE cores in $100 \mathrm{bp}$ non-overlapping windows is superimposed (line) illustrating the overlap between AhR enriched regions and DRE cores in the proximal promoter region.

DRE core, but does not eliminate the possibility of AhR interaction through DNA looping or protein tethering. Interestingly, the fold enrichment values for regions without the DRE core were consistently lower than those with a DRE core, suggesting AhR interactions are stronger in regions containing a DRE.

\section{DRE Analysis of AhR Enriched Regions}

TCDD-elicited changes in gene expression are mediated through AhR signaling via binding to the substitution intolerant DRE core sequence (5'-GCGTG-3'). Overlaying TCDD-induced AhR enrichment with DRE core locations throughout the mouse genome [8] identified $57.8 \%$ and $48.5 \%$ of the enriched regions did not contain a DRE core regions at 2 and 24 hrs, respectively (Table 2 and Figures 5A-B). Other promoter-specific ChIP-chip studies have also reported DRE cores in $\sim 50 \%$ of the AhR enriched regions $[33,35]$. The remaining enriched regions possessed at least one and as many as 16 DRE cores (Table 2). AhR enriched regions with or without a DRE core exhibited similar widths and levels of enrichment.

Matrix similarity (MS) scores have been calculated for each 19 bp DRE sequence within the mouse genome using a position weight matrix (PWM) constructed from bona fide functional DREs [8]. Of the 6,595 significant AhR enriched regions containing a DRE core $(6,093$ from $2 \mathrm{hr}$ and 502 from $24 \mathrm{hr}$ ), $90.7 \%$ were within $500 \mathrm{bp}$ of a DRE core (i.e. distance of maximum enrichment within the region to an underlying DRE core) with half of these positions located within 135 bp of a DRE core. However, only $8.3 \%$ and $17.8 \%$ of the AhR enriched regions at 2 and 24 hrs, respectively, possessed a putative functional (high scoring) DRE sequence (MS score $\geq 0.8473$ ) suggesting the AhR may bind other degenerate sequence elements.

AhR binding to an alternate response element (5'$\left.\mathrm{CATGN}_{6} \mathrm{C}[\mathrm{T} \mid \mathrm{A}] \mathrm{TG}-3^{\prime}\right)$ has also been reported [40,41]. Of the 8,353 and 472 enriched regions at 2 and 24 hrs, respectively, that did not contain a DRE core, 482 and 237 , respectively, contained the alternate DRE sequence (5.8\% and 50.2\%, respectively). The higher incidence of AhR enriched regions at $24 \mathrm{hrs}$ containing the alternate response element may represent tertiary AhR binding sites resulting from conformational changes and crowding of the promoter with the general transcription machinery $[42,43]$.

\section{Transcription Factor Binding Site Over-Representation Analysis}

Significantly AhR enriched regions were computationally analyzed for over-represented response elements for known TF binding site (TFBS) families using RegionMiner (Genomatix). DREs as well other sites for early growth response (EGR), E2F, nuclear respiratory factor 1 (NRF1), nuclear receptor subfamily 2 factors (NR2F/COUP-TF) and peroxisome proliferator-activated receptor (PPAR) were over-represented within AhR enriched regions (Table 3; complete list of over-represented TFBS are provided in Additional Files 6 and 7). Many of these TF sites were enriched proximally to a DRE core (i.e. within 10-50 bp; Additional File 8) suggesting possible interactions. Studies have previously reported interactions between AhR and many of these TFs $[34,44,45]$. For example, AhR complexes with EGR-1 following treatment of human HUVEC cells with high glucose concentrations [45]. In addition, AhR aggregates with E2F1 to inhibit E2F1-induced apoptosis [46]. AhR also directly interacts with COUP-TF to repress ER-mediated gene expression [47].

\section{De Novo Motif Analysis}

Approximately $50 \%$ of enriched regions lacked the DRE core sequence (Figures 5A-B) suggesting AhR interacts with DNA using alternate strategies. De novo motif analysis of these regions using the Gibbs motif sampler in CisGenome identified over-representation of comparable repetitive elements in both the intergenic and intragenic DNA regions (Additional File 9). Comparison of overrepresented non-repetitive motifs to existing TF binding motifs in JASPAR and TRANSFAC $[48,49]$ using STAMP [50] identified similarities to COUP-TF, hepatocyte nuclear factor 4 (HNF4), liver receptor homolog 1 (LRH1/NR5A2) and PPAR binding sites (Figure 6). Interestingly, COUP-TF and HNF4 belong to the NR2F 
A) List of AhR enriched regions ${ }^{a}$ identified by ChIP-chip analysis at 2 hrs confirmed by ChIP-PCR. Three representive enrichments with and without a DRE core were chosen from each genomic region.

\begin{tabular}{|c|c|c|c|c|c|c|c|c|c|}
\hline $\begin{array}{l}\text { Enrichment } \\
\text { ID }\end{array}$ & $\begin{array}{l}\text { Genomic } \\
\text { region }\end{array}$ & $\mathrm{DRE}^{\mathrm{b}}$ & $\begin{array}{l}\text { Gene } \\
\text { Symbol }\end{array}$ & RefSeq & $\begin{array}{l}\text { Enrichment } \\
\text { ID }\end{array}$ & $\begin{array}{l}\text { Genomic } \\
\text { region }\end{array}$ & $\mathrm{DRE}^{\mathrm{b}}$ & $\begin{array}{l}\text { Gene } \\
\text { Symbol }\end{array}$ & RefSeq \\
\hline $\begin{array}{l}\text { AhR_106 } \\
\text { AhR_129 } \\
\text { AhR_130 }\end{array}$ & Intergenic & yes & NA & NA & $\begin{array}{l}\text { AhR_82 } \\
\text { AhR_159 } \\
\text { AhR_216 }\end{array}$ & Intergenic & no & NA & NA \\
\hline $\begin{array}{l}\text { AhR_1 } \\
\text { AhR_2 } \\
\text { AhR_11 }\end{array}$ & $\begin{array}{l}10 \mathrm{~kb} \\
\text { upstream }\end{array}$ & yes & $\begin{array}{l}\text { Cyp1a1 } \\
\text { Tiparp } \\
\text { Cyp1b1 }\end{array}$ & $\begin{array}{l}\text { NM_009992 } \\
\text { NM_178892 } \\
\text { NM_009994 }\end{array}$ & $\begin{array}{l}\text { AhR_4 } \\
\text { AhR_35 } \\
\text { AhR_1456 }\end{array}$ & $\begin{array}{l}10 \mathrm{~kb} \\
\text { upstream }\end{array}$ & no & $\begin{array}{l}\text { Slc35d1 } \\
\text { Pcp4l1 } \\
\text { Cyp1a1 }\end{array}$ & $\begin{array}{l}\text { NM_177732 } \\
\text { NM_025557 } \\
\text { NM_009992 }\end{array}$ \\
\hline $\begin{array}{l}\text { AhR_196 } \\
\text { AhR_198 } \\
\text { AhR_507 }\end{array}$ & 5' UTR & yes & $\begin{array}{l}\text { Myo1b } \\
\text { Edc3 } \\
\text { Sfxn1 }\end{array}$ & $\begin{array}{l}\text { NM_010863 } \\
\text { NM_153799 } \\
\text { NM_027324 }\end{array}$ & $\begin{array}{l}\text { AhR_51 } \\
\text { AhR_581 } \\
\text { AhR_857 }\end{array}$ & 5' UTR & no & $\begin{array}{l}\text { Bach2 } \\
\text { Atxn1 } \\
\text { Tbc1d16 }\end{array}$ & $\begin{array}{l}\text { NM_007521 } \\
\text { NM_009124 } \\
\text { NM_172443 }\end{array}$ \\
\hline $\begin{array}{l}\text { AhR_21 } \\
\text { AhR_151 } \\
\text { AhR_236 }\end{array}$ & CDS & yes & $\begin{array}{l}\text { Prom1 } \\
\text { Pkm2 } \\
\text { Lmo7 }\end{array}$ & $\begin{array}{l}\text { NM_008935 } \\
\text { NM_011099 } \\
\text { NM_201529 }\end{array}$ & $\begin{array}{l}\text { AhR_146 } \\
\text { AhR_201 } \\
\text { AhR_908 }\end{array}$ & CDS & no & $\begin{array}{l}\text { Npc1 } \\
\text { Derl1 } \\
\text { Erbb3 }\end{array}$ & $\begin{array}{l}\text { NM_008720 } \\
\text { NM_024207 } \\
\text { NM_010153 }\end{array}$ \\
\hline $\begin{array}{l}\text { AhR_476 } \\
\text { AhR_714 } \\
\text { AhR_907 }\end{array}$ & 3' UTR & yes & $\begin{array}{l}\text { Al464131 } \\
\text { Irf2bp2 } \\
\text { Wipf3 }\end{array}$ & $\begin{array}{l}\text { NM_001085515 } \\
\text { NM_001164598 } \\
\text { NM_001167860 }\end{array}$ & $\begin{array}{l}\text { AhR_143 } \\
\text { AhR_3220 } \\
\text { AhR_5515 }\end{array}$ & 3' UTR & no & $\begin{array}{l}\text { Rbm4 } \\
\text { Irs1 } \\
\text { Cebpa }\end{array}$ & $\begin{array}{l}\text { NM_009032 } \\
\text { NM_010570 } \\
\text { NM_007678 }\end{array}$ \\
\hline
\end{tabular}

B)
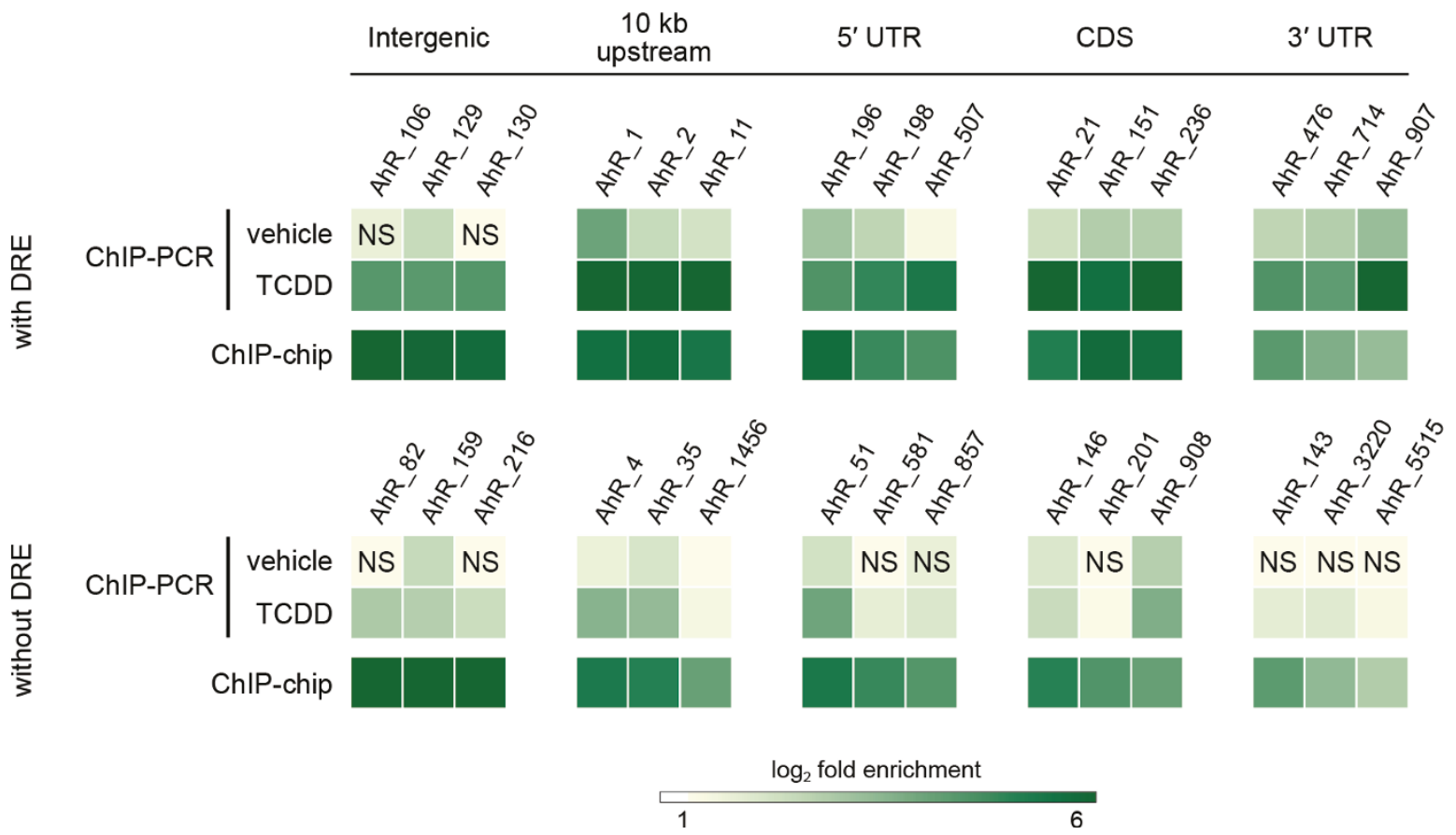

Figure 4 Confirmation of hepatic TCDD-induced AhR enrichment identified by ChIP-chip analysis (FDR $<0.01$ ) at 2 hrs by ChIP-PCR Selected regions were chosen for verification based on position relative to a TSS, ChIP-chip fold enrichment and the presence or lack of a DRE core within the region of enrichment (A). Immunoprecipitated DNA was measured by QRTPCR and AhR enrichment was calculated as fold induction above lgG controls. The color intensity of each box represents the mean value of three independent replicates. NS = not significant compared to lgG controls $(p<0.05) .2$ hr ChIP-chip enrichment values are provided in Additional File 1.

family identified in the TFBS over-representation analysis of all AhR enriched regions (Table 3). The presence of these binding motifs in non-DRE containing regions of AhR enrichment further suggests that AhR-DNA interactions occur through a tethering mechanism involving other TFs or by tertiary looping of DNA. 
Table 2 Distribution of DRE cores in AhR enriched regions $^{\mathrm{a}}$

\begin{tabular}{ccc}
\hline Number of DRE cores $^{\mathbf{b}}$ & \multicolumn{2}{c}{ Number of AhR enriched regions } \\
\cline { 2 - 3 } & $\mathbf{2} \mathbf{~ h r}$ & $\mathbf{2 4} \mathbf{~ h r}$ \\
\hline 0 & 8,353 & 472 \\
1 & 3,705 & 289 \\
2 & 1,372 & 121 \\
3 & 544 & 46 \\
4 & 223 & 16 \\
5 & 109 & 12 \\
6 & 67 & 7 \\
7 & 25 & 5 \\
8 & 15 & 0 \\
9 & 11 & 3 \\
10 & 7 & 1 \\
11 & 5 & 0 \\
12 & 3 & 1 \\
13 & 0 & 0 \\
14 & 3 & 1 \\
15 & 3 & 0 \\
16 & 1 & 0 \\
\hline Total & $\mathbf{1 4 , 4 4 6}$ & $\mathbf{9 7 4}$ \\
\hline
\end{tabular}

${ }^{\mathrm{a}}$ AhR enriched regions with a FDR $<0.01$

b 5 '-GCGTG-3' core sequence

\section{Gene Level Analysis of AhR Enrichment}

Of the 10,369 enrichments identified in the intragenic DNA regions, $43.8 \%(4,544 / 10,369)$ contained a DRE core at $2 \mathrm{hrs}$, and $52.4 \%(332 / 634)$ at $24 \mathrm{hrs}$ (Figure 5, areas shaded blue). These intragenic AhR enriched regions mapped to 5,307 and 591 unique genes at 2 and 24 hrs, respectively (AhR targeted genes are provided as gene annotated enriched regions in Additional Files 1 and 2). Molecular and cellular functional analysis using Ingenuity Pathway Analysis (IPA) found these genes to be associated with lipid and carbohydrate metabolism, small molecule biochemistry, cell cycle and gene expression based on a Fisher's Exact Test p-value $<0.01$ (Figure 7; Additional Files 10 and 11 list the most significant over represented biological functions at 2 and $24 \mathrm{hrs}$ ). Furthermore, 63.5 and $56.2 \%$ of the genes associated with AhR enrichment at 2 and $24 \mathrm{hrs}$, respectively, contained a DRE core within the region of enrichment (Figure 8). The higher percentage of genes containing a DRE core compared to enriched regions with a DRE core is due to multiple regions of AhR enrichment associated with a single gene (as illustrated for Cypla1 in Figure 1). The remaining genes $(36.5 \%$ and $54.8 \%$ at 2 and 24 hrs, respectively) with significant AhR enrichment were targeted independently of a DRE core.

At both 2 and 24 hrs, 575 genes had AhR enrichment, with 513 possessing DRE cores in the AhR enriched region (Figure $8 C$ ). Only 16 genes exhibited AhR enrichment solely at $24 \mathrm{hrs}$, with three containing a DRE core.
In contrast, 4,732 genes possessed significant AhR enrichment with $60.4 \%(2,856)$ containing a DRE core within the region of enrichment at $2 \mathrm{hrs}$. Due to the large overlap of enriched regions at 2 and $24 \mathrm{hrs}$, the remaining analysis focuses predominantly on the AhR enrichment at $2 \mathrm{hr}$.

\section{Comparison of Transcriptional Responses with AhR Enrichment}

Gene expression analysis at 2, 4, 8, 12, 18, 24, 72, and 168 hrs identified 1,896 unique differentially expressed genes ( $\mid$ fold change $\mid \geq 1.5$ and $\mathrm{P} 1(\mathrm{t})>0.999)$ at one or more time points. Of the 1,896 TCDD-responsive genes, 900 genes (47.5\%) possessed significant AhR enrichment within the intragenic region (10 kb upstream of the TSS to the end of the transcript). Moreover, of the 900 genes exhibiting $\mathrm{AhR}$ enrichment at 2 hrs, 625 contained a DRE core sequence, suggesting these responses are AhR-mediated. The remaining 275 differentially expressed genes were not associated with a AhR enriched region containing a DRE core, and may be secondary responses. In order to concisely visualize the integration of the DRE, ChIP-chip and gene expression analyses, Circos plots were generated for the genome and individual chromosomes (Figure 9 and Additional File 12). The plots further illustrate the diversity in AhR enrichment locations in relation to the genomic position of dysregulated genes. Further analysis of the responsive genes found that most were induced by TCDD (Table 4) at all time points. Greater than $82 \%$ of the induced genes at 2 or 4 hrs had significant AhR enrichment, and more than $62 \%$ of them contained at least one DRE core suggesting that regulation is DRE-dependent fashion. In contrast, only 35\% of the 691 genes induced at $168 \mathrm{hrs}$, exhibited AhR enrichment with $26 \%$ possessing a DRE core suggesting that these are secondary gene expression responses. Interestingly, down-regulated genes associated with AhR enrichment were relatively consistent across all time points. Approximately one third of the downregulated genes appear to be AhR regulated with DRE involvement.

Functional analysis of the 900 differentially expressed genes associated with AhR enrichment was performed using DAVID [51]. The most over-represented functions were associated with lipid metabolic processes (enrichment score of 7.34, Table 5), consistent with the induced fatty liver phenotype $[52,53]$. IPA analysis of these genes also identified lipid metabolism as an enriched molecular and cellular function (Fisher's Exact Test p-value $<0.01$; Figure 10; Additional File 13 provides a list of the most significant biological functions). In addition, de novo motif analysis (Figure 6) identified binding sites for TFs associated with lipid metabolism and transport. The 
A) $2 \mathrm{hr}$ 14,446 AhR enriched regions

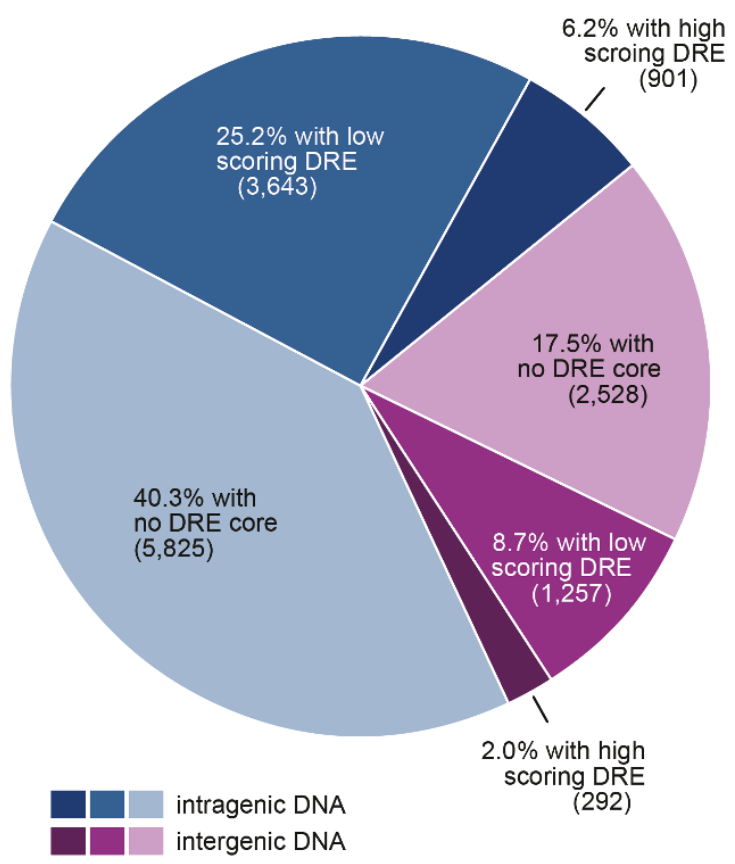

B)

$$
\begin{aligned}
& 24 \mathrm{hr} \\
& 974 \mathrm{AhR} \text { enriched regions }
\end{aligned}
$$

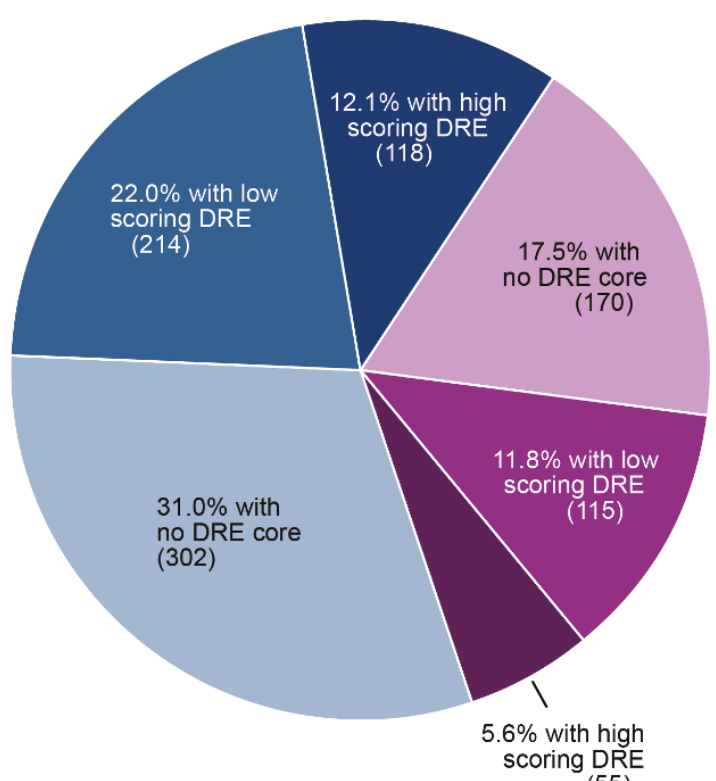

(55)

C)

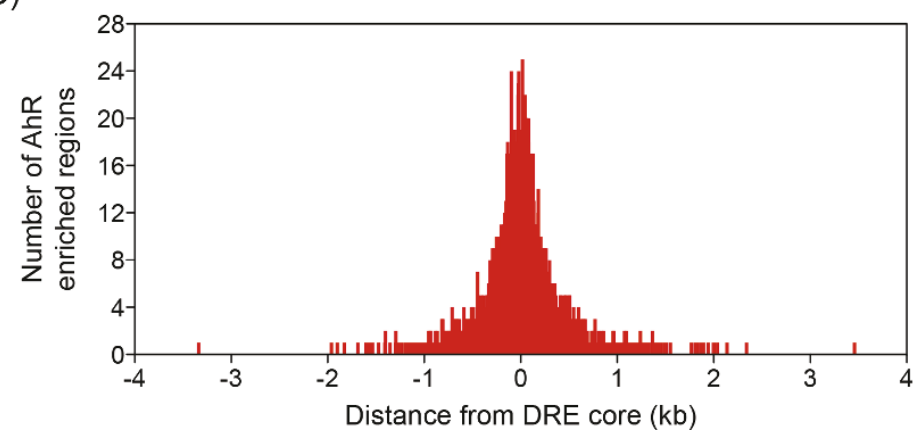

Figure 5 Mapping TCDD-induced AhR enriched regions (FDR $<0.01)$ with DRE locations. Regions of enrichment identified in the intergenic (purple) and intragenic (blue) DNA regions of the genome at 2 hrs (A) and 24 hrs (B) were searched for high scoring (putative functional) DRE sequences (matrix similarity score $\geq 0.8473$; dark blue and dark purple segments) and low scoring DRE sequences (matrix similarity score < 0.8473; mid blue and mid purple segments) using a position weight matrix developed from bona fide functional DREs [8]. Light blue and light purple segments represent regions with no DRE core sequence. A total of 6,595 enriched regions (6,093 at 2 hrs and 502 at 24 hrs) contained at least one DRE core (5'-GCGTG-3'). 50\% of these regions were within $135 \mathrm{bp}$ of a DRE core (based on the location of maximum enrichment within the enriched region; $\mathbf{C}$.

induction of AhR regulated xenobiotic enzymes, such as cytochrome P450s, glutathione S-transferases (Gsts) and UDP-glucuronosyltransferases (Ugts), hallmarks of TCDD exposure, were also identified as an enriched cluster (enrichment score of 3.54).

Although AhR mediates the expression of enzymes involved in xenobiotic metabolizing enzymes, including $\mathrm{NADP}(\mathrm{H})$ dehydrogenase, quinone 1 (Nqo1) and UDPglucose dehydrogenase $(U g d h)$ as well as several Ugt and Gst isoforms, they are also regulated by nuclear factor, erythroid derived 2, like 2 (Nrf2) via antioxidant response elements in response to oxidative stress [54,55]. Recent studies with AhR and Nrf2 null mice report that TCDD induction of Nqo1 is AhR and Nrf2 dependent [56]. Furthermore, specific Ugt and Gst isoforms induced by TCDD require Nrf2. Collectively, these responses are referred to as the "TCDD-inducible AhR-Nrf2 gene battery." ChIP-chip and gene expression 
Table 3 Significantly over-represent transcription factor module families in TCDD-induced AhR enriched regions ${ }^{a}$

\begin{tabular}{|c|c|c|c|c|c|c|c|c|c|}
\hline \multirow{2}{*}{$\begin{array}{l}\text { TF Module } \\
\text { Family }\end{array}$} & \multirow[t]{2}{*}{ Module Description } & \multicolumn{4}{|c|}{$2 \mathrm{hr}$ AhR enriched regions } & \multicolumn{4}{|c|}{$24 \mathrm{hr}$ AhR enriched regions } \\
\hline & & $\begin{array}{l}\text { \# of } \\
\text { matches }\end{array}$ & $\begin{array}{l}\text { Expected \# } \\
\text { of matches }\end{array}$ & $\begin{array}{l}\text { Over- } \\
\text { representaion }^{\mathbf{b}}\end{array}$ & $\begin{array}{c}\text { Z- } \\
\text { Score }\end{array}$ & $\begin{array}{c}\text { \# of } \\
\text { matches }\end{array}$ & $\begin{array}{l}\text { Expected \# } \\
\text { of matches }\end{array}$ & $\begin{array}{c}\text { Over- }^{-} \\
\text {representaion }^{\mathbf{b}}\end{array}$ & $\begin{array}{c}\text { Z- } \\
\text { Score } \\
\end{array}$ \\
\hline AHR & AhR-ARNT heterodimer & 9,447 & $4,278.30$ & 2.21 & 79.03 & 851 & 297.44 & 2.86 & 32.07 \\
\hline SP1 & GC-Box factors SP1/GC & 19,356 & $12,839.04$ & 1.51 & 57.54 & 1,346 & 892.61 & 1.51 & 15.17 \\
\hline HIF & $\begin{array}{l}\text { Hypoxia inducible factor, } \\
\text { bHLH/PAS protein family }\end{array}$ & 8,763 & $4,841.13$ & 1.81 & 56.37 & 569 & 336.57 & 1.69 & 12.64 \\
\hline $\mathrm{E} 2 \mathrm{~F}$ & $\begin{array}{l}\text { E2F-Myc activator/cell cycle } \\
\text { regulator }\end{array}$ & 18,247 & $12,444.88$ & 1.47 & 52.04 & 1,266 & 865.21 & 1.46 & 13.62 \\
\hline ZBP & Zinc binding protein factors & 25,542 & $18,518.20$ & 1.38 & 51.65 & 1,739 & $1,287.45$ & 1.35 & 12.58 \\
\hline NRF1 & Nuclear respiratory factor 1 & 3.475 & $1,494.81$ & 2.32 & 51.21 & 252 & 103.92 & 2.42 & 14.48 \\
\hline ZF5 & ZF5 POZ domain zinc finger & 3,156 & $1,442.92$ & 2.19 & 45.09 & 205 & 100.32 & 2.04 & 10.40 \\
\hline NF1 & Nuclear factor 1 & 13,047 & $8,876.90$ & 1.47 & 44.27 & 886 & 617.15 & 1.44 & 10.81 \\
\hline $\mathrm{NR} 2 \mathrm{~F}$ & $\begin{array}{l}\text { Nuclear receptor subfamily } 2 \\
\text { factors }\end{array}$ & 44,774 & $36,390.64$ & 1.23 & 44.02 & 3,180 & $2,530.00$ & 1.26 & 12.93 \\
\hline EGR & $\begin{array}{l}\text { EGR/nerve growth factor } \\
\text { included protein } c\end{array}$ & 22,224 & $16,794.62$ & 1.32 & 41.92 & 1,541 & $1,167.62$ & 1.32 & 11. \\
\hline PPAR & $\begin{array}{l}\text { Peroxisome proliferator- } \\
\text { activated receptor }\end{array}$ & 24,808 & $19,035.70$ & 1.30 & 41.87 & 1,752 & $1,323.43$ & 1.32 & 11.78 \\
\hline RXR & $\begin{array}{l}\text { RXR heterodimer binding } \\
\text { sites }\end{array}$ & 41,027 & $33,441.00$ & 1.23 & 41.54 & 2,932 & $2,324.93$ & 1.26 & 12.60 \\
\hline WHN & Winged helix binding sites & 3,030 & $1,477.23$ & 2.05 & 40.39 & 206 & 102.70 & 2.01 & 10.14 \\
\hline
\end{tabular}

${ }^{a}$ AhR enriched regions with a FDR $<0.01$

${ }^{\mathrm{b}}$ total number of matches in enriched regions/expected number of matches in genome

Complete list of over-represented TF module families are provided in Additional Files 6 and 7

analysis indicates that Nqo1, Gstm1, Gstm2, Ugdh and Nrf2 induction is associated with AhR enrichment. Although supportive of the Nrf2-dependency model, these data do not distinguish if these are secondary responses mediated by Nrf2 alone, or involve an AhR-
Nrf2 interaction. In contrast, Gsta1 and Ugt2b35 induction occurred independently of AhR enrichment, suggesting they may only be dependent on Nrf2 [56].

Immune cell accumulation following a single acute dose of TCDD at $168 \mathrm{hrs}$ is presumed to be a secondary

A)

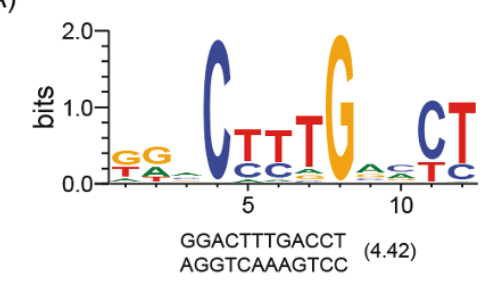

\begin{tabular}{|c|c|c|}
\hline \multicolumn{3}{|c|}{ TRANSFAC } \\
\hline TFBS motif & E-value & Alignment \\
\hline COUP-TF & $2.27 \mathrm{E}-13$ & $\begin{array}{l}\text {-AGNNCAAAGNYM } \\
\text { NNGKNCAAAGKTC }\end{array}$ \\
\hline HNF4 & $1.25 \mathrm{E}-11$ & $\begin{array}{l}\text { KRNCTTTGNNCT } \\
\text { GAMCTTTGNCCN }\end{array}$ \\
\hline PPARa-RXRa & $1.40 \mathrm{E}-10$ & $\begin{array}{l}----- \text { AGNNCAAAGNYM- } \\
\text { WRAWCTAGGNCAAAGGTCA }\end{array}$ \\
\hline GCNF & $5.13 \mathrm{E}-09$ & $\begin{array}{l}\text {--KRNCTTTGNNCT--- } \\
\text { NNTGAMCTTGAACTTGA }\end{array}$ \\
\hline
\end{tabular}

\begin{tabular}{lcc}
\multicolumn{2}{c}{ JASPAR } \\
\hline TFBS motif & E-value & Alignment \\
\hline COUP-TF & $8.28 \mathrm{E}-13$ & $\begin{array}{c}\text {-AGNNCAAAGNYM- } \\
\text { NNGKNCAAAGKTCA } \\
\text {-KRNCTTTGNNCT } \\
\text { TGNMCTTTGNNCY }\end{array}$ \\
LXR-RXRa & $1.93 \mathrm{E}-10$ & $\begin{array}{c}--- \text { KRNCTTTGNNCT-- } \\
\text { STTGACCTTTGACTTT }\end{array}$ \\
PPAR-RXRa & $6.60 \mathrm{E}-06$ & $\begin{array}{l}- \text {---KRNCTTTGNNCT--- } \\
\text { NNNTGACTTTGACCYCNNN }\end{array}$ \\
\hline
\end{tabular}

B)

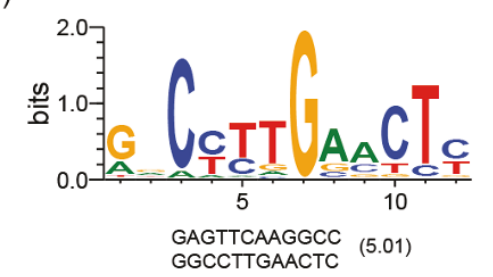

\begin{tabular}{lcc}
\multicolumn{3}{c}{ TRANSFAC } \\
\hline TFBS motif & E-value & Alignment \\
\hline GCNF & $1.50 E-11$ & $\begin{array}{l}-- \text { RAGKTCAARGNC--- } \\
\text { TCAAGTTCAAGKTCANN } \\
\text { GNCYTTGAMCTY }\end{array}$ \\
PXR & $8.87 E-09$ & $\begin{array}{l}---- \text { TGAACTN } \\
\text { Pax-6 }\end{array}$ \\
LRH1 & $1.32 \mathrm{E}-08$ & $\begin{array}{l}\text { RAGKTCAARGNC- } \\
\text { KAGTTCCAGGTCA }\end{array}$ \\
\hline
\end{tabular}

\begin{tabular}{|c|c|c|}
\hline \multicolumn{3}{|c|}{ JASPAR } \\
\hline TFBS motif & E-value & Alignment \\
\hline COUP-TF & $7.33 \mathrm{E}-07$ & $\begin{array}{l}\text { RAGKTCAARGNC-- } \\
\text { NNGKNCAAAGKTCA }\end{array}$ \\
\hline LXR-RXR $\alpha$ & $2.29 \mathrm{E}-05$ & $\begin{array}{l}\text {----GNCYTTGAMCTY- } \\
\text { STTGACCTTTGACCTTT }\end{array}$ \\
\hline Tcfep2l1 & $4.82 \mathrm{E}-05$ & $\begin{array}{l}\text {-GNCYTTGAMCTY- } \\
\text { CYGGNTNNRNCYGG }\end{array}$ \\
\hline PPAR-RXRa & $5.30 \mathrm{E}-03$ & $\begin{array}{l}----- \text { GNCYTTGAMCTY--- } \\
\text { NNNTGACCTTTGACYCNNN }\end{array}$ \\
\hline
\end{tabular}

Figure 6 De novo motif analysis of intragenic (A) and intergenic (B) AhR enriched regions lacking a DRE core. The non-repetitive overrepresented motifs from each region are shown with their consensus and reverse complement sequence, and the Gibbs motif sampler score. Over-represented motifs were associated with specific TFBSs in JASPAR and TRANSFAC based on the consensus sequence alignments and Evalue scores. 


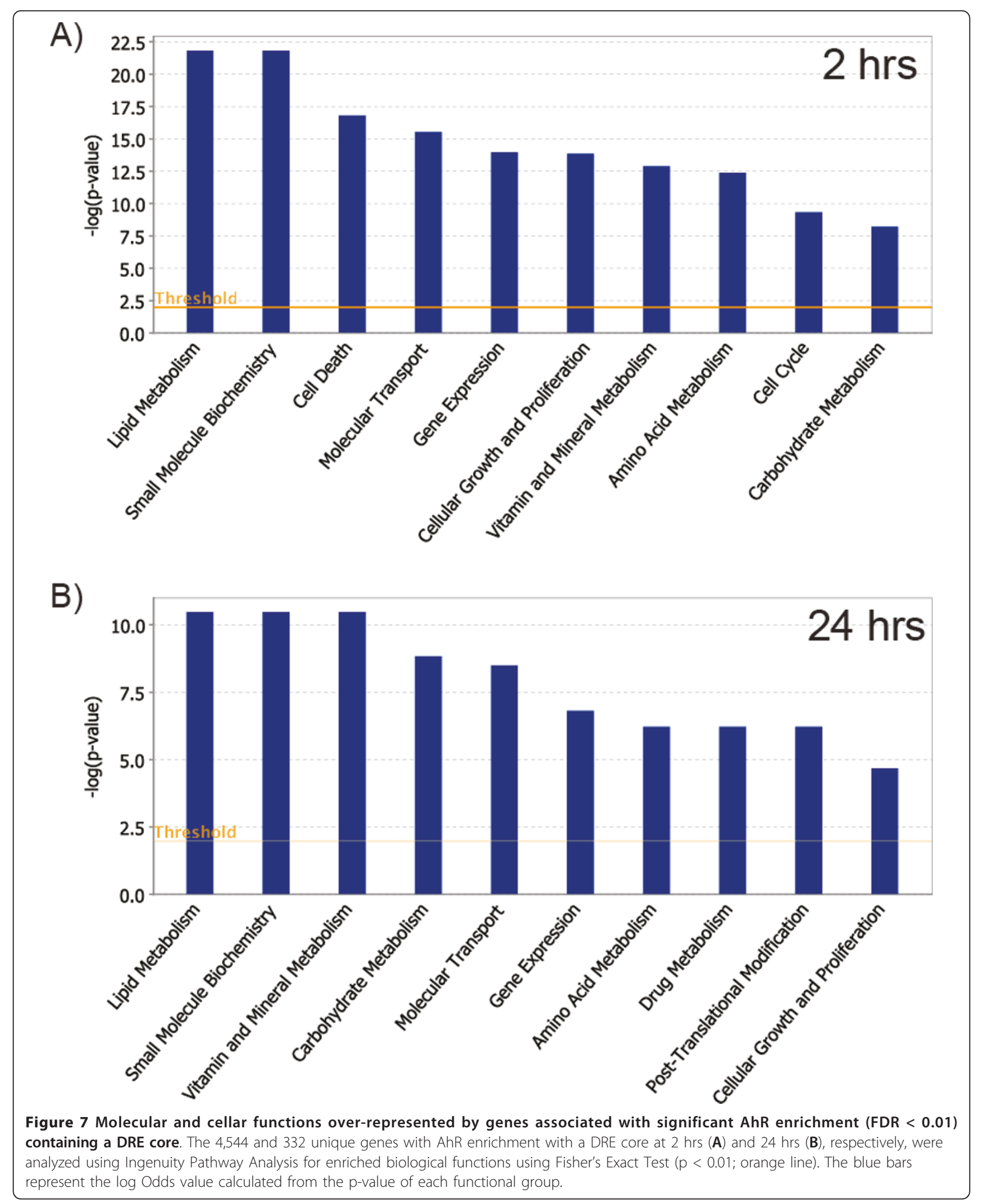




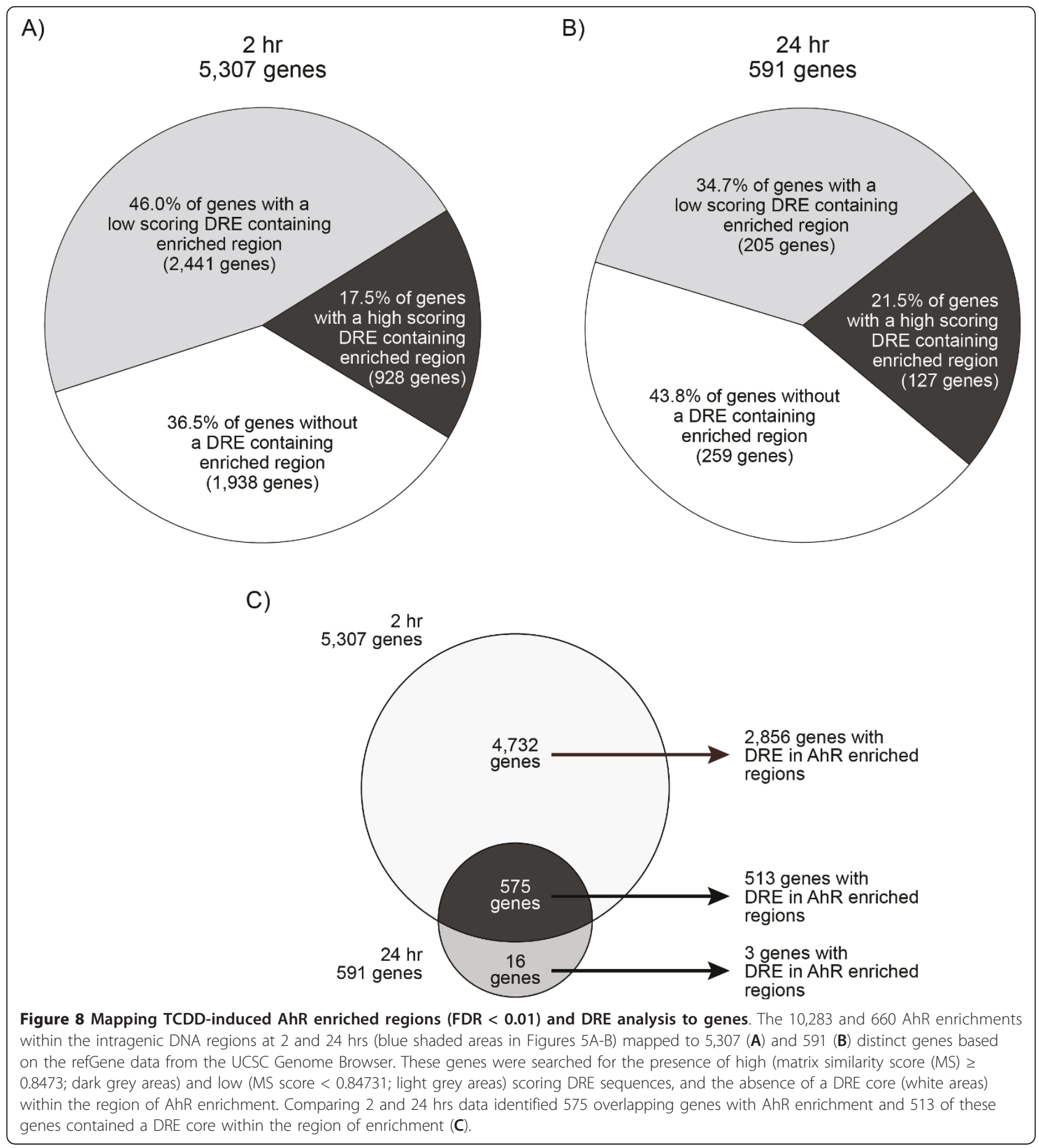

response to hepatic injury or fatty acid accumulation [52,53]. DAVID analysis of genes induced at $168 \mathrm{hrs}$ identified multiple over-represented immune-related clusters (enrichment scores $>2$ ). However, several of the genes including complement component 1, q subcomponent, beta polypeptide $(C 1 q b)$, CD36 antigen $(C d 36)$, complement component $4 \mathrm{~A}(\mathrm{C} 4 \mathrm{a})$ and interferon regulatory factor 8 (Irf8), did not exhibit accompanying AhR enrichment within their intragenic region (10 kb upstream of the TSS to the end of the 3' UTR). Only 26 out of 105 differentially regulated genes in the enriched immune clusters exhibited AhR enrichment. Collectively, these data suggest that gene expression associated with immune function is a consequence of immune cell infiltration into the liver. 


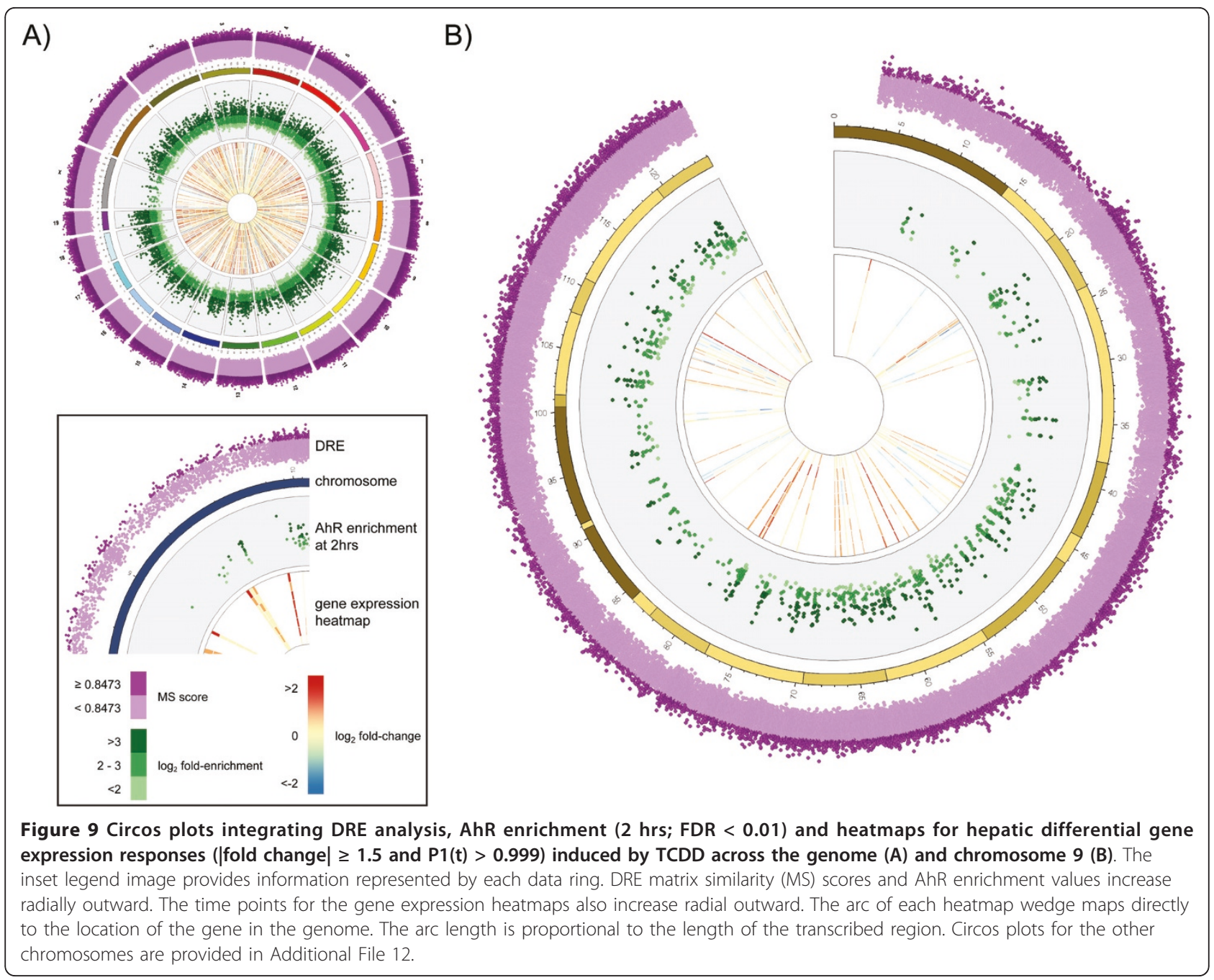

\section{Discussion}

This study further elucidates the role of the AhR in mediating the hepatic effects of TCDD in C57BL6 mice. Recent studies have mapped AhR binding using promoter-focused ChIP-chip arrays and found that $\sim 50 \%$ of the AhR enriched regions were devoid of the DRE core [32-34]. The lack of a DRE core in regions of $A h R$ enrichment was also reported in a AhR

Table 4 Distribution and AhR enrichment and DRE analysis of differentially expressed genes elicited by TCDD

\begin{tabular}{|c|c|c|c|c|c|c|c|c|c|c|}
\hline & & & $\begin{array}{c}2 \\
\mathrm{hr}\end{array}$ & $\begin{array}{c}4 \\
\mathrm{hr}\end{array}$ & $\begin{array}{l}8 \\
\mathrm{hr}\end{array}$ & $\begin{array}{l}12 \\
\mathrm{hr}\end{array}$ & $\begin{array}{l}18 \\
\mathrm{hr}\end{array}$ & $\begin{array}{l}24 \\
\mathrm{hr}\end{array}$ & $\begin{array}{l}72 \\
\mathrm{hr}\end{array}$ & $\begin{array}{c}168 \\
\mathrm{hr}\end{array}$ \\
\hline \multirow{6}{*}{$\begin{array}{l}\text { Number of differentially expressed } \\
\text { genes }^{a}\end{array}$} & Up-regulated & Total & 68 & 255 & 341 & 218 & 236 & 287 & 267 & 719 \\
\hline & & With AhR enrichment ${ }^{\mathrm{b}}$ & 55 & 200 & 202 & 148 & 172 & 186 & 164 & 243 \\
\hline & & $\begin{array}{l}\text { With AhR enrichment }{ }^{b}+\text { DRE } \\
\text { core }^{c}\end{array}$ & 47 & 168 & 171 & 126 & 146 & 156 & 135 & 181 \\
\hline & $\begin{array}{l}\text { Down- } \\
\text { regulated }\end{array}$ & Total & 18 & 233 & 116 & 168 & 105 & 237 & 261 & 218 \\
\hline & & With AhR enrichment ${ }^{\mathrm{b}}$ & 10 & 123 & 76 & 102 & 59 & 131 & 137 & 123 \\
\hline & & $\begin{array}{l}\text { With AhR enrichment }{ }^{b}+\text { DRE } \\
\text { core }^{c}\end{array}$ & 6 & 79 & 49 & 63 & 30 & 72 & 79 & 70 \\
\hline
\end{tabular}

\footnotetext{
a fold-change $\mid \geq 1.5$ and $\mathrm{P} 1(\mathrm{t})>0.999$

${ }^{b}$ AhR enriched regions at 2 hrs with FDR $<0.01$

c 5 '-GCGTG-3' core sequence within AhR enriched region
} 


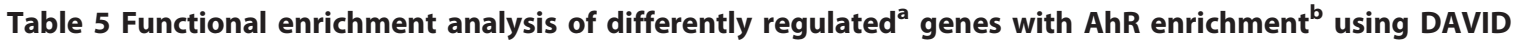

\begin{tabular}{|c|c|c|c|c|}
\hline Category & Team & Gene Count & Fold enrichment & P-value \\
\hline \multicolumn{5}{|c|}{ Enrichment Score: 7.34} \\
\hline GOTERM_BP_3 & GO:0006629 lipid metabolic process & 76 & 2.23 & $5.53 \mathrm{E}-11$ \\
\hline GOTERM_BP_3 & GO:0044255 cellular lipid metabolic process & 53 & 2.23 & 7.80E-08 \\
\hline GOTERM_BP_3 & GO:0008610 lipid biosynthetic process & 32 & 2.30 & $2.28 \mathrm{E}-05$ \\
\hline \multicolumn{5}{|c|}{ Enrichment Score:4.12 } \\
\hline GOTERM_BP_3 & GO:0048523 negative regulation of cellular process & 94 & 1.60 & 4.46E-06 \\
\hline GOTERM_BP_3 & GO:0048519 negative regulation of biological process & 101 & 1.54 & 7.83E-06 \\
\hline GOTERM_BP_3 & GO:0031324 negative regulation of cellular metabolic process & 45 & 1.85 & 8.99E-05 \\
\hline GOTERM_BP_3 & GO:0051172 negative regulation of nitrogen compound metabolic process & 39 & 1.96 & 9.68E-05 \\
\hline GOTERM_BP_3 & GO:0009890 negative regulation of biosynthetic process & 40 & 1.86 & 2.33E-04 \\
\hline GOTERM_BP_3 & GO:0009892 negative regulation of metabolic process & 46 & 1.74 & 3.20E-04 \\
\hline GOTERM_BP_3 & GO:0010605 negative regulation of macromolecule metabolic process & 43 & 1.72 & $6.88 \mathrm{E}-04$ \\
\hline \multicolumn{5}{|c|}{ Enrichment Score: 3.54} \\
\hline GOTERM_BP_3 & GO:0009410 response to xenobiotic stimulus & 8 & 10.59 & $3.54 \mathrm{E}-06$ \\
\hline GOTERM_BP_3 & GO:0006805 xenobiotic metabolic process & 7 & 11.59 & $1.12 \mathrm{E}-05$ \\
\hline GOTERM_BP_3 & GO:0018894 dibenzo-p-dioxin metabolic process & 3 & 19.86 & 7.31E-03 \\
\hline GOTERM_BP_3 & GO:0009404 toxin metabolic process & 3 & 11.92 & $2.28 \mathrm{E}-02$ \\
\hline \multicolumn{5}{|c|}{ Enrichment Score: 2.70} \\
\hline GOTERM_BP_3 & GO:0051272 positive regulation of call motion & 9 & 4.58 & $6.00 \mathrm{E}-04$ \\
\hline GOTERM_BP_3 & GO:0051270 regulation of cell motion & 15 & 2.84 & 7.55E-04 \\
\hline GOTERM_BP_3 & GO:0040017 Positive regulation of locomotion & 9 & 4.26 & $1.01 \mathrm{E}-03$ \\
\hline GOTERM_BP_3 & GO:0030334 regulation of cell migration & 13 & 2.87 & $1.76 \mathrm{E}-03$ \\
\hline GOTERM_BP_3 & GO:0040012 regulation of locomotion & 13 & 2.39 & 7.93E-03 \\
\hline GOTERM_BP_3 & GO:0040012 regulation of localization & 32 & 1.61 & 9.36E-03 \\
\hline \multicolumn{5}{|c|}{ Enrichment Score: 2.55} \\
\hline GOTERM_BP_3 & GO:0048518 positive regulation of biological process & 106 & 1.44 & 7.45E-05 \\
\hline GOTERM_BP_3 & GO:0048522 positive regulation of cellular process & 94 & 1.45 & 2.03E-04 \\
\hline GOTERM_BP_3 & GO:0009893 positive regulation of metabolic process & 51 & 1.53 & 2.64E-03 \\
\hline GOTERM_BP_3 & GO:0010604 positive regulation of macromolecule metabolic process & 48 & 1.54 & 3.02E-03 \\
\hline GOTERM_BP_3 & GO:0031325 positive regulation of cellular & 47 & 1.48 & $6.67 \mathrm{E}-03$ \\
\hline GOTERM_BP_3 & GO:0009891 positive regulation of biosynthetic & 38 & 1.38 & 3.96E-02 \\
\hline GOTERM_BP_3 & GO:0031325 positive regulation of nitrogen compound metabolic process & 36 & 1.39 & 4.40E-02 \\
\hline \multicolumn{5}{|c|}{ Enrichment Score: 2.44} \\
\hline GOTERM_BP_3 & GO:0005996 monosaccharide metabolic process & 21 & 2.27 & 9.50E-04 \\
\hline GOTERM_BP_3 & GO:0005975 carbohydrate metabolic process & 37 & 1.67 & 2.63E-03 \\
\hline GOTERM_BP_3 & GO:0016051 carbohydrate biosynthetic process & 11 & 2.70 & 7.19E-03 \\
\hline GOTERM_BP_3 & GO:0044262 cellular carbohydrate metabolic process & 27 & 1.70 & 9.34E-03 \\
\hline
\end{tabular}

${ }^{a} \mid$ fold-change $\mid \geq 1.5$ and $\mathrm{P} 1(\mathrm{t})>0.999$ at one or more time points

${ }^{\mathrm{b}}$ AhR enriched regions at 2 hrs with FDR $<0.01$

genome-wide ChIP-chip study performed in mouse CH12.LX cells [57]. ChIP-seq experiments for other TFs have also demonstrated enrichment in remote genome regions, which may serve important regulatory roles $[10,11,14,17]$. Collectively these data suggest the AhR uses different mechanisms to regulate gene expression. Moreover, the integration of genome-wide in silico DRE search, with de novo motif analysis and TCDD-elicited hepatic temporal gene expression data has further elucidated the hepatic AhR gene regulatory network.
ChIP-chip analysis identified 14,446 TCDD-induced AhR regions at $2 \mathrm{hrs}$ and 974 regions at $24 \mathrm{hrs}$, consistent with the rapid nuclear export and subsequent degradation of the AhR following TCDD activation [37]. Approximately half of these regions were within intragenic regions $(10 \mathrm{~kb}$ upstream of a TSS to the end of the 3' UTR). Furthermore, 25\% of these enriched regions at $2 \mathrm{hrs}$ and $19 \%$ at $24 \mathrm{hrs}$ were within $2 \mathrm{~kb}$ of a TSS, indicating that a large subset of AhR enrichment occurs adjacent to a TSS. Unlike other studies that report a normal distribution of TF binding centered around the 


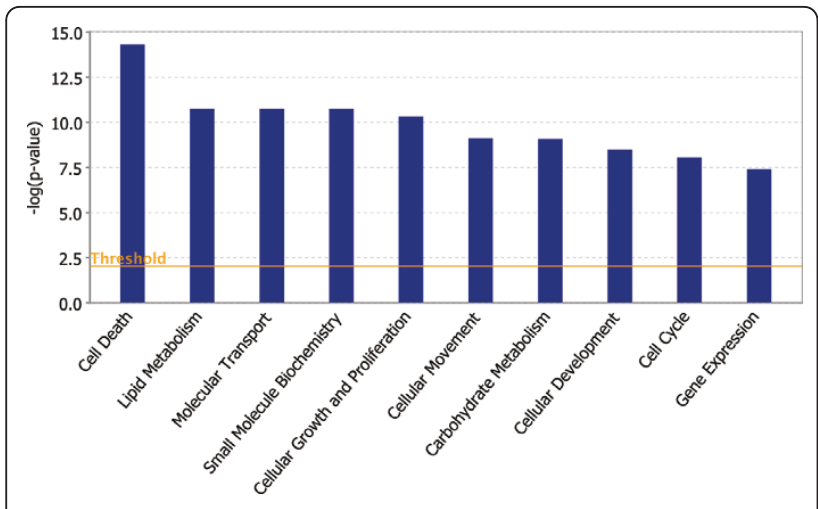

Figure 10 Molecular and cellar functions over-represented by differentially regulated genes (|fold change $\mid \geq 1.5, \mathrm{P} 1(\mathrm{t})>$ 0.999) associated with significant AhR enrichment (FDR $<0.01$ ) at 2 hrs. The 900 differentially regulated genes with AhR enrichment were analyzed using Ingenuity Pathway Analysis for enriched biological functions using Fisher's Exact Test $(p<0.01$; orange line). The blue bars represent the log Odds value calculated from the $p$-value of each functional group.

TSS [15,58-60], the AhR density profile exhibited a cleft immediately adjacent to the TSS, possibly to accommodate recruited transcriptional machinery.

Although most AhR enrichment regions are intragenic, a significant number are located in distal intergenic regions (i.e. 4,163 of 14,446 at $2 \mathrm{hrs}$ and 344 of 974 at 24 hrs). Studies with the ER, p53 and forkhead box protein A1 $[10,11,14,17]$ suggest distal TF binding may have distinct regulatory roles. Binding proximal to the TSS is presumed to stabilize the general transcriptional machinery, while distal binding regulates transcription by a looping mechanism or by altering chromatin structure $[9,61,62]$. Consequently, AhR binding outside of the proximal promoter region may have important regulatory roles that remain largely uninvestigated.

Comparing AhR enriched regions with DRE cores revealed that their intergenic, intragenic and genic (10 kb upstream, UTRs, and CDS) density distributions were similar. The greatest density of AhR enrichment associated with a DRE core occurred within the proximal promoter. Both exhibited comparable distribution profiles except for the cleft in enrichment at the TSS. The decrease in AhR enrichment at the TSS coincides with RNA polymerase II binding at the TSSs [10] of transcriptionally responsive genes. Although TCDD-elicited differential gene expression is thought to be mediated by the substitution intolerant DRE core sequence (5'-GCGTG3 '), only $\sim 50 \%$ of the AhR enriched regions contained a DRE core, consistent with findings in other promoter targeted AhR ChIP-chip studies [33,35] (Lo et al., in submission). Moreover, relatively few alternative AhR response elements (5'-CATGN 6 C $\left.[\mathrm{T} \mid \mathrm{A}] \mathrm{TG}-3^{\prime}\right)[40,41]$ were identified in $A h R$ enriched regions lacking a DRE core sequence. Enrichment in regions lacking DRE cores provides additional evidence of AhR-DNA interactions that don not involve the basic bHLH domain [63], such as tethering to other DNA interacting TFs and/or tertiary interactions with looping DNA.

Integration of gene expression, ChIP-chip, and DRE distribution data suggests that $\sim 35 \%$ of all differentially expressed hepatic genes are mediated by direct AhR binding to a DRE. Consequently, $65 \%$ of the gene expression responses elicited by TCDD do not involve direct AhR binding to a DRE. However, TF binding analyses based on tiling arrays is limited by the extent of probe coverage (Figure 1). Genomic regions lacking probe coverage may falsely inflate the number of DRE-absent AhR enriched regions, thus underestimating the number of AhR regulated genes involving a DRE. Furthermore, the analyses may not be exhaustive due to the technical limitations of ChIP-chip assay coupled with the conservative FDR threshold used to identify statistically significant signals, which may have excluded some positive signals. These limitations of the technology could be addressed in ChIP-seq experiments, which have greater resolution and sensitivity $[64,65]$. The shorter sequence reads would improve resolution, but may also identify fewer regions containing a DRE. The higher sensitivity of ChIP-seq could also identify additional regions of AhR enrichment. ChIP-seq studies could also confirm AhR binding in these genomic regions in either a DRE-dependent or independent manner.

TCDD induces hepatic vacuolization and lipid accumulation with differential gene expression associated with fatty acid metabolism and transport $[25,53]$. Independent functional annotation analysis of differentially expressed genes with significant AhR enrichment using DAVID and IPA identified over-represented processes related to fatty acid and lipid metabolism. Computational analysis also identified over-represented binding motifs for TFs involved in the regulation of lipid and cholesterol metabolism, including sites for HNF4, LXR, PXR, PPAR and COUP-TF. COUP-TF is a potent repressor that antagonizes transcriptional responses mediated by other nuclear receptors including HNF4, PPAR, ER, RAR and VDR [66]. For example, COUP-TF antagonizes HNF4 $\alpha$-mediated responses by binding $\mathrm{HNF} 4 \alpha$ response elements [67-71]. Furthermore, AhR interactions with COUP-TF repress ER-mediated gene expression responses [47]. Therefore, AhR interactions with COUP-TF may regulate lipid and fatty acid metabolism by blocking HNF4 $\alpha$ target gene expression (Figure 10A). Coincidentally, the HNF4 binding motif is over represented within AhR enriched regions lacking a DRE core.

Consistent with this proposed mechanism, several HNF4 $\alpha$ regulated genes, including Cyp $7 a 1$ and Gck, exhibited AhR enrichment and were repressed by 
TCDD. Cyp7a1 is the rate-limiting enzyme in the bile acid biosynthetic pathway that converts cholesterol into bile acids. Transgenic mice over-expressing Cyp7a1 are protected from high-fat diet induced obesity, fatty liver and insulin resistance [72]. Moreover, a genetic deficiency of Cyp7a1 in humans results in hyperlipidemia [73]. Gck phosphorylates glucose in the initial step of glycolysis. Mutations in Gck that reduce kinase activity are associated with insulin resistance and maturity onset diabetes of young 2 (MODY2) in humans [74-76]. Furthermore, mice over-expressing Gck are resistant to MODY2 [77]. The down-regulation of Cyp7a1 and Gck, possibly due to AhR - COUP-TF interactions at HNF4a response elements, is consistent TCDD-induced hepatic lipid accumulation in mice. Interestingly, TCDD exposure has been linked to diabetes and metabolic syndrome in humans [78-84]. Studies examining AhRCOUP-TF interactions and their effects on HNF4 target gene expression are being investigated further.

\section{Conclusion}

This study identified the genome-wide locations of TCDD-induced hepatic AhR enrichment in vivo and incorporates DRE distribution and differential gene expression data to further elucidate the hepatic AhR regulatory network. In addition to identifying interactions in regions associated with genes, AhR enrichment in distal non-coding intergenic regions was characterized. The functional significance of these distal interactions is unknown but intergenic binding has been reported for other TFs, and warrants further investigation. Moreover, only $\sim 50 \%$ of all AhR enriched regions involved a DRE, suggesting that indirect AhR binding to DNA plays a significant role in the AhR regulatory network.

\section{Methods}

\section{Animal Handling and Treatment}

Hepatic tissue samples from immature female ovariectomized C57BL/6 mice obtained from a previous study [53] were used for both ChIP assays at 2 and $24 \mathrm{hrs}$, and gene expression analyses across all time points. Briefly, mice were orally gavaged with $30 \mu \mathrm{g} / \mathrm{kg}$ TCDD and sacrificed by cervical dislocation at $2,4,8,12,18,24,72$ or $168 \mathrm{hrs}$ postdose. Tissues were removed, weighed, and multiple samples ( 100 mg each) were flash frozen in liquid nitrogen and stored at $-80^{\circ} \mathrm{C}$ until further use.

\section{Chromatin Immunoprecipitation (ChIP) and ChIP-chip Experiments}

ChIP assays were performed as previously described [33] with the following changes. Approximately $100 \mathrm{mg}$ of mouse liver was homogenized in $1 \%$ formaldehyde and incubated for $10 \mathrm{~min}$ at room temperature. Tissue homogenate was centrifuged at 10,000 RPM for $3 \mathrm{~min}$ at $4^{\circ} \mathrm{C}$. Pellet was washed in ice-cold PBS, centrifuged, and resuspended in $900 \mu \mathrm{L}$ of TSEI $(20 \mathrm{mM}$ Tris- $\mathrm{HCl}$ [pH 8.0], $150 \mathrm{mM} \mathrm{NaCl}, 2 \mathrm{mM}$ EDTA, 1\% Triton $\mathrm{X}-100,0.1 \%$ sodium dodecyl sulfate) $+1 \times$ Protease Inhibitor Cocktail (Sigma, St. Louis, MO). Samples were sonicated 12 times for $10 \mathrm{~s}$ each time at $25 \%$ amplitude using a Branson 450 sonifier. Supernatant was transferred to fresh microcentrifuge tubes and incubated with rabbit IgG (5 $\mu$ g; Sigma) and anti-AhR (5 $\mu$ g; SA-210, Biomol) overnight at $4^{\circ} \mathrm{C}$ under gentle agitation. ChIP samples were washed and the DNA was isolated as previously described [33]. For ChIP-chip experiments, immunoprecipitated DNA isolated following immunoprecipitation with anti-AhR of liver extracts from TCDD-treated mice was linearly amplified using a whole genome amplification kit according to the manufacturer's instructions (Sigma). Linearly amplified DNA $(7.5 \mu \mathrm{g})$ was fragmented by limited DNAseI digestion and hybridized to Affymetrix GeneChip ${ }^{\circledR}$ mouse 2.0R tiling arrays (Affymetrix, Santa Clara, CA) as previously described [33]. The hybridization and washing steps were performed according to the manufacturer's protocol at the Centre for Applied Genomics (Toronto, Canada). Data were normalized and analyzed using CisGenome and mapped against mouse genome version $\mathrm{mm} 9$ [36]. Enriched regions with a false discovery rate (FDR) of 1.0\% (0.01) were determined by comparing triplicate samples of $A h R_{T C D D}$ to triplicate $\operatorname{IgG}_{\mathrm{TCDD}}$ using a moving average (MA) approach with default settings in TileMap v2 [85]. Regions were merged if the gap between them was $<300 \mathrm{bp}$ and the number of probes failing to reach the cut-off was $<5$. Regions were discarded if they were $<120$ bp or did not contain at least 5 continuous probes above the cut-off. ChIPed DNA was purified using the PCR purification kit from BioBasic Inc. (Markham, ON) and quantified using quantitative real-time PCR (QRTPCR) (KAPA SYBR Fast qPCR Master Mix; KAPA Biosystems, Toronto, ON) (ChIPPCR). Fold enrichment values were calculated relative to IgG controls. ChIP-PCR primer sequences are provided in Additional File 14.

\section{ChIP-chip Location Analysis}

The mouse genomic assembly ( $\mathrm{mm} 9)$ and associated annotation within the refGene and refLink databases were downloaded from the UCSC Genome Browser [86]. Individual segments of a gene region (i.e. the $10 \mathrm{~kb}$ sequence upstream of a TSS, the 5' and 3' UTRs and the CDS) for each mature gene encoding reference sequence (RefSeqs with NM prefixed identifiers) were determined using the genomic coordinates within the refGene databases (Additional File 3). Intragenic DNA regions within 
the genomes were computationally identified by merging overlapping gene regions (Additional File 3) from both strands of the genome, and the DNA between adjacent intragenic regions are defined as the non-transcribed intergenic DNA regions (Additional File 3). AhR enrichment densities were calculated based on the number of significant enriched regions occurring in an interrogated region (e.g. intergenic DNA region or 5' UTR) divided by the total sum of the region length. Gene annotation associated with each RefSeq sequence was derived from the refLink database in the UCSC Genome Browser.

\section{Transcription Factor Motif Analysis}

The locations of AhR enrichment were compared against 5'-GCGTG-3' DRE core sequence locations in the mouse genome [8]. Identification of TF motifs over-represented in regions containing a DRE core were performed using the default parameter settings in RegionMiner, a program within the Genomatix suite of applications http://www.genomatix.de that contains an extensive database of TF binding motifs. Identified module families and individual matrices with $\mathrm{z}$-scores $>3$ were considered significant [87]. De novo motif discovery was performed using the Gibbs motif sampler in CisGenome on AhR regions of enrichment sequences not containing a DRE. Matrices for overrepresented motifs were compared to existing TF binding motifs in JASPAR and TRANSFAC $[48,49]$ using STAMP [50].

\section{Comparison with Microarray Gene Expression}

Results from the ChIP-chip and DRE analysis were integrated with whole-genome gene expression profiling data from mice orally gavaged with $30 \mu \mathrm{g} / \mathrm{kg}$ TCDD using $4 \times$ $44 \mathrm{k}$ whole-genome oligonucleotide arrays from Agilent Technologies (Santa Clara, CA) [8]. The genomic locations of the differentially responsive genes (|fold change| $\geq 1.5$ and $\mathrm{P} 1(\mathrm{t})>0.999)$ were obtained for each RefSeq sequence associated with the gene from the refGene database in the UCSC Genome Browser. Circos plots [88] were generated to visualize the locations of DRE cores, regions of AhR enrichment and temporal heatmaps of temporal gene expression responses.

\section{Functional Annotation and Pathway Analysis}

Functional annotation clustering of Gene Ontology (GO) terms for genes associated with significant AhR enrichment was performed using DAVID (Database for Annotation, Visualization, and Integrated Discovery) [51]. In addition, the regions were analyzed using Ingenuity Pathway Analysis (IPA; http://www.ingenuity. $\mathrm{com} /$ ) to identify over-represented molecular and cellular functions based on the Fisher's Exact Test p-value $<0.01$.

\section{Additional material}

Additional file 1: Genomic location, gene annotation and enrichment values of significant (FDR $<0.01)$ TCDD-induced AhR enrichment at $\mathbf{2}$ hrs. Detailed results of the AhR ChIP-chip analysis that include the genomic location and TCDD-induced enrichment values, and the gene annotation of enrichment peaks located within the $10 \mathrm{~kb}$ upstream and transcribed region of a gene.

Additional file 2: Genomic location, gene annotation and enrichment values of significant (FDR $<0.01$ ) TCDD-induced AhR enrichment at $\mathbf{2 4} \mathrm{hrs}$. Detailed results of the AhR ChIP-chip analysis that include the genomic location and TCDD-induced enrichment values, and the gene annotation of enrichment peaks located within the $10 \mathrm{~kb}$ upstream and transcribed region of a gene.

Additional file 3: Definitions of various genomic regions used to map regions of $A$ hR enrichment. A) Genomic locations from the UCSC Genome Browser refGene database were used to obtain sequences for $10 \mathrm{~kb}$ region upstream of the TSS, the $5^{\prime}$ and $3^{\prime}$ UTRs, and the CDS of every known human, mouse and rat RefSeq sequence. A gene region is defined as the sequence spanning the region $10 \mathrm{~kb}$ upstream of a TSS through to the end of the $3^{\prime}$ UTR. B) Intragenic DNA regions in a genome were determined by combining the non-overlapping gene regions. For example, gene regions of tissue specific isoforms of a gene that have different TSS positions were merged to determine the longest spanning range (genes $C \& C^{\prime}$ and genes $E$ \& E'). Additionally,

overlapping genes on both strands of the genome were also merged (genes $B+E+E^{\prime}$ ). Non-transcribed DNA segments that span the regions between adjacent intragenic regions are defined as the intergenic DNA regions.

Additional file 4: TCDD-induced AhR enrichment (FDR $<0.01$ ) density across the mouse genome at 2 hrs. The density of significant AhR enrichment (per Mbp) at 2 hrs were calculated for each of the defined genomic regions across the individual chromosomes.

Additional file 5: TCDD-induced AhR enrichment (FDR $<0.01$ ) density across the mouse genome at $\mathbf{2 4}$ hrs. The density of significant AhR enrichment (per Mbp) at 24 hrs were calculated for each of the defined genomic regions across the individual chromosomes.

Additional file 6: Transcription factor binding site analysis of significant TCDD-induced AhR enrichment (FDR $<0.01$ ) at 2 hrs. DNA sequences for the regions of significant AhR enrichment at $2 \mathrm{hrs}$ were analyzed for transcription factor (TF) binding site motif overrepresentation using RegionMiner. The results list the TF matrices and their corresponding over-representation and z-score value.

Additional file 7: Transcription factor binding site analysis of significant TCDD-induced AhR enrichment (FDR < 0.01) at $24 \mathrm{hrs}$ DNA sequences for the regions of significant AhR enrichment at 24 hrs were analyzed for transcription factor (TF) binding site motif overrepresentation using RegionMiner. The results list the TF matrices and their corresponding over-representation and z-score value.

Additional file 8: Over-representation of transcription factor binding motifs located proximally (10-50 bp) of a DRE in a significantly AhR enriched region (FDR $<0.01$ ). DNA sequences for the regions of significant AhR enrichment at 2 and 24 hrs possessing a DRE core sequence (5'-GCGTG-3') were analyzed for transcription factor (TF) binding site motif over-representation using RegionMiner. The results list the TF matrices and their corresponding over-representation and z-score value.

Additional file 9: Repetitive sequence elements identified in the de novo motif analysis of significant intragenic and intergenic AhR enriched regions (FDR $<0.01$ ) lacking a DRE core. The repetitive over-represented motifs from each region are shown with their consensus and reverse complement sequence, and the Gibbs motif sampler score.

Additional file 10: Pathway analysis of genes associated with DREcontaining regions of $A$ hR enrichment (FDR $<0.01$ ) at 2 hrs. List of the most significant Bio-Functions $(p<0.01)$ identified using Ingenuity Pathway Analysis for the genes associated with a significant AhR 
enriched region (FDR < 0.01) containing a DRE core $\left(5^{\prime}-G C G T G-3 '\right)$ at 2 hrs.

Additional file 11: Pathway analysis of genes associated with DREcontaining regions of AhR enrichment (FDR $<0.01)$ at $24 \mathrm{hrs}$. List of the most significant Bio-Functions $(p<0.01)$ identified using Ingenuity Pathway Analysis for the genes associated with a significant AhR enriched region (FDR < 0.01) containing a DRE core $\left(5^{\prime}\right.$-GCGTG-3') at 24 hrs.

Additional file 12: Circos plots integrating DRE analysis, AhR enrichment $(2 \mathrm{hrs} ; \mathrm{FDR}<0.01)$ and heatmaps for hepatic differential gene expression responses (|fold change $\mid \geq 1.5$ and $\mathrm{P} 1$ $(t)>0.999)$ induced by TCDD across the genome. Circos plots illustrate the ideograms for each individual chromosome and the entire genome and integrate the results of the DRE, ChIP-chip and gene expression analyses.

Additional file 13: Pathway analysis of differentially regulated genes (|fold change $\geq 1.5$ and $\mathrm{P} 1(\mathrm{t})>0.999)$ associated with regions of $A h R$ enrichment $(F D R<0.01)$ at 2 hrs. List of the most significant Bio-Functions $(p<0.01)$ identified using Ingenuity Pathway Analysis for TCDD-elicited gene expression responses (|fold change| $\geq 1.5$ and $\mathrm{P} 1(\mathrm{t})>0.999)$ associated with a significant AhR enriched region (FDR $<0.01$ ) containing a DRE core (5'-GCGTG-3') at 24 hrs

Additional file 14: Primer sequences used to verify $2 \mathrm{hr}$ ChIP-chip responses. QRTPCR primers used to verify AhR enriched regions isolated from the $2 \mathrm{hr}$ ChIP-chip.

\section{Acknowledgements}

This work was supported by the National Institute of Environmental Health Sciences Superfund Basic Research Program [P42ES04911 to TRZ] and by the Canadian Institute of Health Research [MOP-82715 to JM]. JM is a recipient of the Canadian Institute of Health Research New Investigator Award. TRZ is partially supported by the Michigan Agricultural Extension Station.

\section{Author details}

'Department of Biochemistry \& Molecular Biology, Michigan State University, East Lansing, Ml, 48824, USA. ${ }^{2}$ Department of Pharmacology \& Toxicology, University of Toronto, Toronto, Ontario, M5S 1A8, Canada. ${ }^{3}$ Center for Integrative Toxicology, Michigan State University, East Lansing, MI, 48824, USA.

\section{Authors' contributions}

ED performed the computational analyses and integration of the ChIP-chip data with the computational DRE and microarray gene expression analyses, and the initial preparation of the manuscript. JM optimized and performed the ChIP experiments, and normalized the ChIP-chip data. TL and RL validated the ChIP-chip results with ChIP-PCR from regions identified by ED. TRZ oversaw the completion of the study. All the authors have given final approval of the version to be published.

Received: 17 September 2010 Accepted: 15 July 2011 Published: 15 July 2011

\section{References}

1. Gu Y, Hogenesch J, Bradfield C: The PAS superfamily: sensors of environmental and developmental signals. Annu Rev Pharmacol Toxicol 2000, 40:519-561.

2. Denison MS, Heath-Pagliuso S: The Ah receptor: a regulator of the biochemical and toxicological actions of structurally diverse chemicals. Bulletin of environmental contamination and toxicology 1998, 61:557-568.

3. Poland A, Knutson JC: 2,3,7,8-tetrachlorodibenzo-p-dioxin and related halogenated aromatic hydrocarbons: examination of the mechanism of toxicity. Annu Rev Pharmacol Toxicol 1982, 22:517-554.

4. Hankinson O: The aryl hydrocarbon receptor complex. Annu Rev Pharmacol Toxicol 1995, 35:307-340.

5. Okey AB, Vella LM, Harper PA: Detection and characterization of a low affinity form of cytosolic Ah receptor in livers of mice nonresponsive to induction of cytochrome P1-450 by 3-methylcholanthrene. Molecular Pharmacology 1989, 35:823-830.

6. Gonzalez F, Fernandez-Salguero P: The aryl hydrocarbon receptor: studies using the AHR-null mice. Drug Metab Dispos 1998, 26:1194-1198.

7. Swanson $\mathrm{H}$, Chan W, Bradfield C: DNA binding specificities and pairing rules of the Ah receptor, ARNT, and SIM proteins. J Biol Chem 1995, 270:26292-26302.

8. Dere E, Forgacs AL, Zacharewski TR, Burgoon LD: Genome-Wide Computational Analysis of Dioxin Response Element Location and Distribution in the Human, Mouse, and Rat Genomes. Chem Res Toxicol 2011.

9. Farnham PJ: Insights from genomic profiling of transcription factors. Nat Rev Genet 2009, 10:605-616.

10. Carroll JS, Meyer CA, Song J, Li W, Geistlinger TR, Eeckhoute J, Brodsky AS, Keeton EK, Fertuck KC, Hall GF, et al: Genome-wide analysis of estrogen receptor binding sites. Nature Genetics 2006, 38:1289-1297.

11. Carroll JS, Liu XS, Brodsky AS, Li W, Meyer CA, Szary AJ, Eeckhoute J, Shao W, Hestermann EV, Geistlinger TR, et al: Chromosome-wide mapping of estrogen receptor binding reveals long-range regulation requiring the forkhead protein FoxA1. Cell 2005, 122:33-43.

12. Deblois G, Hall JA, Perry M-C, Laganière J, Ghahremani M, Park M, Hallett M, Giguère V: Genome-wide identification of direct target genes implicates estrogen-related receptor alpha as a determinant of breast cancer heterogeneity. Cancer Res 2009, 69:6149-6157.

13. Laganière J, Deblois $G$, Lefebvre $C$, Bataille $A R$, Robert $F$, Giguère $V$ : From the Cover: Location analysis of estrogen receptor alpha target promoters reveals that FOXA1 defines a domain of the estrogen response. Proc Natl Acad Sci USA 2005, 102:11651-11656.

14. Lin C-Y, Vega VB, Thomsen JS, Zhang T, Kong SL, Xie M, Chiu KP, Lipovich L, Barnett DH, Stossi F, et al: Whole-genome cartography of estrogen receptor alpha binding sites. PLOS Genet 2007, 3:e87.

15. van der Meer DLM, Degenhardt T, Väisänen $S$, de Groot PJ, Heinäniemi $M$, de Vries SC, Müller M, Carlberg C, Kersten S: Profiling of promoter occupancy by PPARalpha in human hepatoma cells via ChIP-chip analysis. Nucleic Acids Res 2010, 38:2839-2850.

16. Chong HK, Infante AM, Seo Y-K, Jeon T-I, Zhang Y, Edwards PA, Xie X, Osborne TF: Genome-wide interrogation of hepatic FXR reveals an asymmetric IR-1 motif and synergy with LRH-1. Nucleic acids research 2010.

17. Wederell ED, Bilenky M, Cullum R, Thiessen N, Dagpinar M, Delaney A, Varhol R, Zhao Y, Zeng T, Bernier B, et al: Global analysis of in vivo Foxa2binding sites in mouse adult liver using massively parallel sequencing. Nucleic Acids Res 2008, 36:4549-4564.

18. Wei G-H, Badis G, Berger MF, Kivioja T, Palin K, Enge M, Bonke M, Jolma A Varjosalo M, Gehrke AR, et al: Genome-wide analysis of ETS-family DNAbinding in vitro and in vivo. The EMBO journal 2010.

19. Malhotra D, Portales-Casamar E, Singh A, Srivastava S, Arenillas D, Happel C, Shyr C, Wakabayashi N, Kensler TW, Wasserman WW, Biswal S: Global mapping of binding sites for Nrf2 identifies novel targets in cell survival response through ChIP-Seq profiling and network analysis. Nucleic acids research 2010.

20. Schmidt D, Wilson MD, Ballester B, Schwalie PC, Brown GD, Marshall A, Kutter C, Watt S, Martinez-Jimenez CP, Mackay S, et al: Five-vertebrate ChIP-seq reveals the evolutionary dynamics of transcription factor binding. Science 2010, 328:1036-1040.

21. Ramos YFM, Hestand MS, Verlaan M, Krabbendam E, Ariyurek Y, van Galen M, van Dam H, van Ommen G-JB, den Dunnen JT, Zantema A, 't Hoen PAC: Genome-wide assessment of differential roles for p300 and CBP in transcription regulation. Nucleic acids research 2010.

22. Gupta R, Wikramasinghe P, Bhattacharyya A, Perez FA, Pal S, Davuluri RV: Annotation of gene promoters by integrative data-mining of ChIP-seq Pol-II enrichment data. BMC Bioinformatics 2010, 11(Suppl 1):S65.

23. Tallack MR, Whitington T, Shan Yuen W, Wainwright EN, Keys JR, Gardiner BB, Nourbakhsh E, Cloonan N, Grimmond SM, Bailey TL, Perkins AC: A global role for KLF1 in erythropoiesis revealed by ChIP-seq in primary erythroid cells. Genome research 2010.

24. Consortium EP, Birney E, Stamatoyannopoulos JA, Dutta A, Guigó R, Gingeras TR, Margulies EH, Weng Z, Snyder M, Dermitzakis ET, et al: Identification and analysis of functional elements in $1 \%$ of the human genome by the ENCODE pilot project. Nature 2007, 447:799-816.

25. Boverhof DR, Burgoon LD, Tashiro C, Sharratt B, Chittim B, Harkema JR, Mendrick DL, Zacharewski TR: Comparative toxicogenomic analysis of the 
hepatotoxic effects of TCDD in Sprague Dawley rats and C57BL/6 mice. Toxicol Sci 2006, 94:398-416.

26. Dere $E$, Boverhof $D R$, Burgoon LD, Zacharewski TR: In vivo-in vitro toxicogenomic comparison of TCDD-elicited gene expression in Hepa1c1c7 mouse hepatoma cells and C57BL/6 hepatic tissue. BMC Genomics 2006, 7:80

27. Puga A, Maier A, Medvedovic M: The transcriptional signature of dioxin in human hepatoma HepG2 cells. Biochem Pharmacol 2000, 60:1129-1142.

28. Hayes $\mathrm{K}$, Zastrow G, Nukaya M, Pande K, Glover E, Maufort J, Liss A, Liu Y, Moran S, Vollrath A, Bradfield C: Hepatic transcriptional networks induced by exposure to 2,3,7,8-tetrachlorodibenzo-p-dioxin. Chem Res Toxicol 2007, 20:1573-1581.

29. Boutros PC, Yan R, Moffat ID, Pohjanvirta R, Okey AB: Transcriptomic responses to 2,3,7,8-tetrachlorodibenzo-p-dioxin (TCDD) in liver: comparison of rat and mouse. BMC Genomics 2008, 9:419.

30. Flaveny CA, Murray IA, Perdew GH: Differential gene regulation by the human and mouse aryl hydrocarbon receptor. Toxicological sciences: an official journal of the Society of Toxicology 2010, 114:217-225.

31. Whitlock J: Induction of cytochrome P4501A1. Annu Rev Pharmacol Toxicol 1999, 39:103-125.

32. Ahmed S, Valen E, Sandelin A, Matthews J: Dioxin increases the interaction between aryl hydrocarbon receptor and estrogen receptor alpha at human promoters. Toxicol Sci 2009, 111:254-266.

33. Pansoy A, Ahmed S, Valen E, Sandelin A, Matthews J: 3methylcholanthrene induces differential recruitment of aryl hydrocarbon receptor to human promoters. Toxicological sciences: an official journal of the Society of Toxicology 2010.

34. Sartor MA, Schnekenburger M, Marlowe JL, Reichard JF, Wang Y, Fan Y, Ma C, Karyala S, Halbleib D, Liu X, et al: Genomewide analysis of aryl hydrocarbon receptor binding targets reveals an extensive array of gene clusters that control morphogenetic and developmental programs. Environ Health Perspect 2009, 117:1139-1146.

35. Kinehara M, Fukuda I, Yoshida K-I, Ashida H: High-throughput evaluation of aryl hydrocarbon receptor-binding sites selected via chromatin immunoprecipitation-based screening in Hepa-1c1c7 cells stimulated with 2,3,7,8-tetrachlorodibenzo-p-dioxin. Genes Genet Syst 2008, 83:455-468.

36. Ji H, Jiang $H, M a$ W, Johnson DS, Myers RM, Wong WH: An integrated software system for analyzing ChIP-chip and ChIP-seq data. Nat Biotechnol 2008, 26:1293-1300.

37. $\mathrm{Ma} \mathrm{Q}$, Baldwin K: 2,3,7,8-tetrachlorodibenzo-p-dioxin-induced degradation of aryl hydrocarbon receptor (AhR) by the ubiquitinproteasome pathway. Role of the transcription activaton and DNA binding of AhR. J Biol Chem 2000, 275:8432-8438.

38. Pollenz RS: The mechanism of AH receptor protein down-regulation (degradation) and its impact on $\mathrm{AH}$ receptor-mediated gene regulation. Chem Biol Interact 2002, 141:41-61.

39. Song Z, Pollenz R: Ligand-dependent and independent modulation of aryl hydrocarbon receptor localization, degradation, and gene regulation. Mol Pharmacol 2002, 62:806-816.

40. Boutros PC, Moffat ID, Franc MA, Tijet N, Tuomisto J, Pohjanvirta R, Okey AB: Dioxin-responsive AHRE-II gene battery: identification by phylogenetic footprinting. Biochem Biophys Res Commun 2004, 321:707-715.

41. Sogawa K, Numayama-Tsuruta K, Takahashi T, Matsushita N, Miura C, Nikawa J-i, Gotoh O, Kikuchi Y, Fujii-Kuriyama Y: A novel induction mechanism of the rat CYP1A2 gene mediated by Ah receptor-Arnt heterodimer. Biochem Biophys Res Commun 2004, 318:746-755.

42. Richter K, Nessling M, Lichter P: Macromolecular crowding and its potential impact on nuclear function. Biochim Biophys Acta 2008, 1783:2100-2107.

43. Li G-W, Berg OG, Elf J: Effects of macromolecular crowding and DNA looping on gene regulation kinetics. Nature Physics 2009, 5:294.

44. Kobayashi A, Sogawa K, Fujii-Kuriyama Y: Cooperative interaction between AhR.Arnt and Sp1 for the drug-inducible expression of CYP1A1 gene. The Journal of biological chemistry 1996, 271:12310-12316.

45. Dabir P, Marinic TE, Krukovets I, Stenina Ol: Aryl hydrocarbon receptor is activated by glucose and regulates the thrombospondin-1 gene promoter in endothelial cells. Circ Res 2008, 102:1558-1565.

46. Marlowe J, Fan Y, Chang X, Peng L, Knudsen E, Xia Y, Puga A: The aryl hydrocarbon receptor binds to E2F1 and inhibits E2F1-induced apoptosis. Mol Biol Cell 2008, 19:3263-3271.
47. Klinge CM, Kaur K, Swanson HI: The aryl hydrocarbon receptor interacts with estrogen receptor alpha and orphan receptors COUP-TFI and ERRalpha1. Arch Biochem Biophys 2000, 373:163-174.

48. Portales-Casamar E, Thongjuea S, Kwon AT, Arenillas D, Zhao X, Valen E, Yusuf D, Lenhard B, Wasserman WW, Sandelin A: JASPAR 2010: the greatly expanded open-access database of transcription factor binding profiles. Nucleic Acids Research 2010, 38:D105-110.

49. Matys V, Fricke E, Geffers R, Gössling E, Haubrock M, Hehl R, Hornischer K, Karas D, Kel AE, Kel-Margoulis OV, et al: TRANSFAC: transcriptional regulation, from patterns to profiles. Nucleic Acids Res 2003, 31:374-378.

50. Mahony S, Auron PE, Benos PV: DNA familial binding profiles made easy: comparison of various motif alignment and clustering strategies. PLOS Comput Biol 2007, 3:e61.

51. Dennis G, Sherman BT, Hosack DA, Yang J, Gao W, Lane HC, Lempicki RA: DAVID: Database for Annotation, Visualization, and Integrated Discovery. Genome Biol 2003, 4:P3.

52. Kopec AK, Boverhof DR, Burgoon LD, Ibrahim-Aibo D, Harkema JR, Tashiro C, Chittim B, Zacharewski TR: Comparative toxicogenomic examination of the hepatic effects of PCB126 and TCDD in immature, ovariectomized C57BL/6 mice. Toxicol Sci 2008, 102:61-75.

53. Boverhof DR, Burgoon LD, Tashiro C, Chittim B, Harkema JR, Jump DB, Zacharewski TR: Temporal and dose-dependent hepatic gene expression patterns in mice provide new insights into TCDD-Mediated hepatotoxicity. Toxicol Sci 2005, 85:1048-1063.

54. Köhle C, Bock KW: Coordinate regulation of Phase I and II xenobiotic metabolisms by the Ah receptor and Nrf2. Biochemical Pharmacology 2007, 73:1853-1862.

55. Nioi P, Hayes JD: Contribution of $\mathrm{NAD}(\mathrm{P}) \mathrm{H}$ :quinone oxidoreductase 1 to protection against carcinogenesis, and regulation of its gene by the Nrf2 basic-region leucine zipper and the arylhydrocarbon receptor basic helix-loop-helix transcription factors. Mutation research 2004, 555:149-171.

56. Yeager RL, Reisman SA, Aleksunes LM, Klaassen CD: Introducing the "TCDD-inducible AhR-Nrf2 gene battery". Toxicological sciences: an official journal of the Society of Toxicology 2009, 111:238-246.

57. De Abrew KN, Kaminski NE, Thomas RS: An integrated genomic analysis of aryl hydrocarbon receptor-mediated inhibition of B-cell differentiation. Toxicological sciences: an official journal of the Society of Toxicology 2010, 118:454-469.

58. Hamza MS, Pott S, Vega VB, Thomsen JS, Kandhadayar GS, Ng PWP, Chiu KP, Pettersson S, Wei CL, Ruan Y, Liu ET: De-novo identification of PPARgamma/RXR binding sites and direct targets during adipogenesis. PLOS ONE 2009, 4:e4907.

59. O'Geen H, Squazzo SL, lyengar S, Blahnik K, Rinn JL, Chang HY, Green R, Farnham PJ: Genome-wide analysis of KAP1 binding suggests autoregulation of KRAB-ZNFs. PLOS Genet 2007, 3:e89.

60. Xu X, Bieda M, Jin VX, Rabinovich A, Oberley MJ, Green R, Farnham PJ: A comprehensive ChIP-chip analysis of E2F1, E2F4, and E2F6 in normal and tumor cells reveals interchangeable roles of E2F family members. Genome research 2007, 17:1550-1561.

61. Li Q, Barkess G, Qian H: Chromatin looping and the probability of transcription. Trends Genet 2006, 22:197-202.

62. Long X, Miano JM: Remote control of gene expression. J Biol Chem 2007, 282:15941-15945.

63. Murray IA, Morales JL, Flaveny CA, Dinatale BC, Chiaro C, Gowdahalli K, Amin S, Perdew GH: Evidence for ligand-mediated selective modulation of aryl hydrocarbon receptor activity. Molecular Pharmacology 2010, 77:247-254.

64. Gilchrist DA, Fargo DC, Adelman K: Using ChIP-chip and ChIP-seq to study the regulation of gene expression: genome-wide localization studies reveal widespread regulation of transcription elongation. Methods 2009, 48:398-408.

65. Liu ET, Pott S, Huss M: Q\&A: ChIP-seq technologies and the study of gene regulation. BMC Biology 2010, 8:56.

66. Giguère V: Orphan nuclear receptors: from gene to function. Endocr Rev 1999, 20:689-725.

67. Viollet B, Kahn A, Raymondjean M: Protein kinase A-dependent phosphorylation modulates DNA-binding activity of hepatocyte nuclear factor 4. Molecular and Cellular Biology 1997, 17:4208-4219.

68. Mietus-Snyder M, Sladek FM, Ginsburg GS, Kuo CF, Ladias JA, Darnell JE, Karathanasis SK: Antagonism between apolipoprotein Al regulatory protein 1, Ear3/COUP-TF, and hepatocyte nuclear factor 4 modulates 
apolipoprotein CIII gene expression in liver and intestinal cells. Molecular and Cellular Biology 1992, 12:1708-1718.

69. Ladias JA, Hadzopoulou-Cladaras M, Kardassis D, Cardot P, Cheng J,

Zannis V, Cladaras C: Transcriptional regulation of human apolipoprotein genes $\mathrm{ApoB}, \mathrm{ApoCIII}$, and ApoAll by members of the steroid hormone receptor superfamily HNF-4, ARP-1, EAR-2, and EAR-3. The Journal of biological chemistry 1992, 267:15849-15860.

70. Pineda Torra I, Jamshidi Y, Flavell D, Fruchart J-C, Staels B: Characterization of the Human PPAR\{alpha\} Promoter: Identification of a Functional Nuclear Receptor Response Element. Molecular Endocrinology 2002, 16:1013.

71. You M, Fischer M, Cho WK, Crabb D: Transcriptional control of the human aldehyde dehydrogenase 2 promoter by hepatocyte nuclear factor 4 : inhibition by cyclic AMP and COUP transcription factors. Arch Biochem Biophys 2002, 398:79-86.

72. Li T, Owsley E, Matozel M, Hsu P, Novak CM, Chiang JYL: Transgenic expression of cholesterol 7alpha-hydroxylase in the liver prevents highfat diet-induced obesity and insulin resistance in mice. Hepatology 2010, 52:678-690.

73. Pullinger CR, Eng C, Salen G, Shefer S, Batta AK, Erickson SK, Verhagen A, Rivera CR, Mulvihill SJ, Malloy MJ, Kane JP: Human cholesterol 7alphahydroxylase (CYP7A1) deficiency has a hypercholesterolemic phenotype. J Clin Invest 2002, 110:109-117.

74. Caro JF, Triester S, Patel VK, Tapscott EB, Frazier NL, Dohm GL: Liver glucokinase: decreased activity in patients with type II diabetes. Horm Metab Res 1995, 27:19-22.

75. Stoffel M, Froguel P, Takeda J, Zouali H, Vionnet N, Nishi S, Weber IT, Harrison RW, Pilkis SJ, Lesage S: Human glucokinase gene: isolation, characterization, and identification of two missense mutations linked to early-onset non-insulin-dependent (type 2) diabetes mellitus. Proc Natl Acad Sci USA 1992, 89:7698-7702.

76. Marks SD, Couch RM: Identification of two new mutations in the glucokinase gene that result in maturity-onset diabetes of the young. Diabetes Care 2010, 33:e94.

77. Shiota M, Postic C, Fujimoto Y, Jetton TL, Dixon K, Pan D, Grimsby J, Grippo JF, Magnuson MA, Cherrington AD: Glucokinase gene locus transgenic mice are resistant to the development of obesity-induced type 2 diabetes. Diabetes 2001, 50:622-629.

78. Angulo P: Nonalcoholic fatty liver disease. N Engl J Med 2002, 346:1221-1231.

79. Kang HK, Dalager NA, Needham LL, Patterson DG, Lees PSJ, Yates K, Matanoski GM: Health status of Army Chemical Corps Vietnam veterans who sprayed defoliant in Vietnam. Am J Ind Med 2006, 49:875-884.

80. Jones $\mathrm{OAH}$, Maguire ML, Griffin JL: Environmental pollution and diabetes: a neglected association. Lancet 2008, 371:287-288

81. Remillard RBJ, Bunce NJ: Linking dioxins to diabetes: epidemiology and biologic plausibility. Environ Health Perspect 2002, 110:853-858.

82. Cranmer M, Louie S, Kennedy R, Kern P, Fonseca V: Exposure to 2,3,7,8Tetrachlorodibenzo-p-dioxin (TCDD) Is Associated with Hyperinsulinemia and Insulin Resistance. Toxicological Sciences 2000, 56:431.

83. Bertazzi PA, Bernucci I, Brambilla G, Consonni D, Pesatori AC: The Seveso studies on early and long-term effects of dioxin exposure: a review. Environ Health Perspect 1998, 106(Suppl 2):625-633.

84. Henriksen GL, Ketchum NS, Michalek JE, Swaby JA: Serum dioxin and diabetes mellitus in veterans of Operation Ranch Hand. Epidemiology 1997, 8:252-258.

85. Ji H, Wong W: TileMap: create chromosomal map of tiling array hybridizations. Bioinformatics 2005, 21:3629.

86. Rhead B, Karolchik D, Kuhn R, Hinrichs A, Zweig A, Fujita P, Diekhans M, Smith K, Rosenbloom K, Raney B, et al: The UCSC Genome Browser database: update 2010. Nucleic Acids Research 2010, 38:D613.

87. Gerstman BB: Basic Biostatistics: Statistics for Public Health Practice. 1 edition. Sudbury, MA: Jones \& Bartlett Publishers, Inc.; 2007.

88. Krzywinski M, Schein J, Birol I, Connors J, Gascoyne R, Horsman D, Jones SJ, Marra MA: Circos: an information aesthetic for comparative genomics. Genome research 2009, 19:1639-1645.

doi:10.1186/1471-2164-12-365

Cite this article as: Dere et al.: Integration of Genome-Wide Computation DRE Search, AhR ChIP-chip and Gene Expression Analyses of TCDD-Elicited Responses in the Mouse Liver. BMC Genomics 2011 $12: 365$

\section{Submit your next manuscript to BioMed Central and take full advantage of:}

- Convenient online submission

- Thorough peer review

- No space constraints or color figure charges

- Immediate publication on acceptance

- Inclusion in PubMed, CAS, Scopus and Google Scholar

- Research which is freely available for redistribution

Submit your manuscript at www.biomedcentral.com/submit
Biomed Central 